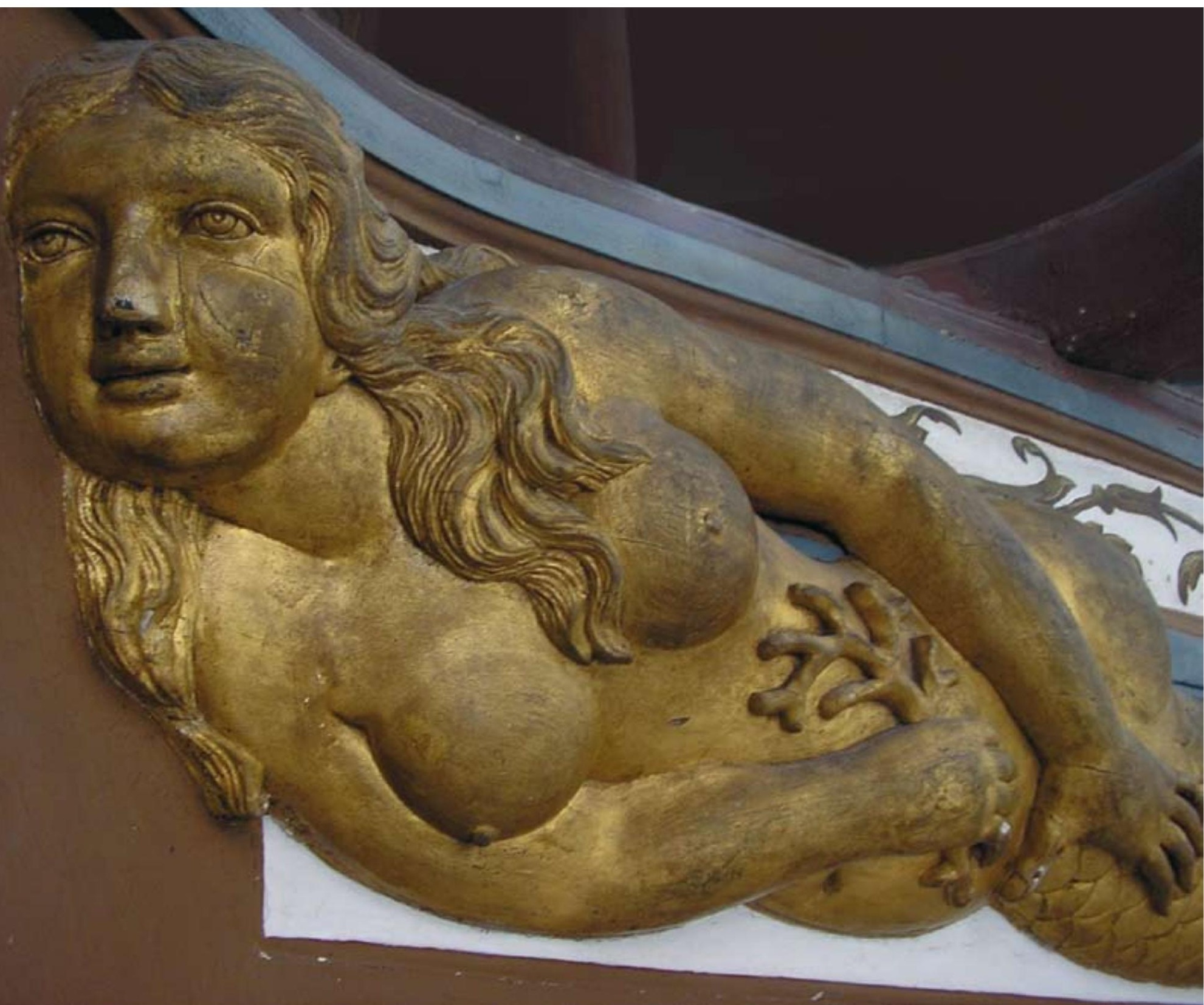

Figura femenina inspirada en la mitología marítima situada en la proa de la Galera de José I. Foto: Lorena Sancho Querol 


\section{El proyecto de conservación de las Galeras Reales portuguesas: un desafío para la museología contemporánea}

Lorena Sancho Querol,

conservadora y museóloga

\section{Resumen}

Adentrarse en la historia maritima portuguesa es iniciar un intenso viaje por un dominio patrimonial extraordinariamente rico, a través del cual podemos descubrir un universo de artes, técnicas y saberes relacionados con el ingenio y con la capacidad creativa de un pueblo de navegantes.

En este artículo analizamos el proceso de creación y la puesta en marcha de un proyecto que camina entre los principios de la nueva museología y los métodos y técnicas utilizados por la conservación de patrimonio en su vertiente contemporánea: el Proyecto de Conservación de las Galeras Reales. El objetivo de esta iniciativa que une a un conjunto diversificado de agentes patrimoniales, es devolver la vida a una colección de patrimonio marítimo del siglo XVIII única en el mundo, que se encuentra actualmente en el Museo de la Marina de Lisboa.

Para ello hemos realizado un estudio comparativo que nos permitiera comprender su relevancia en el panorama mundial. Hemos estudiado su historia, las funciones que asumió a lo largo de más de 200 años, las formas de construcción naval utilizadas y sus elementos decorativos. A partir de este conjunto de datos, hemos creado un sistema sencillo de inventario. Por último, hemos procedido a su restauración, de la que se presentan los resultados obtenidos en sus dos primeras fases.

El camino recorrido nos ha permitido entender cómo el proceso de patrimonialización de una colección como esta se construye cada día y en cada uno de los gestos de quien, en el presente y con la mirada del presente, re-construye el pasado.

\section{Palabras clave}

Conservación / Galeras Reales / Historia / Intervención / Investigación / Museo de la Marina de Lisboa (Portugal) /

Proyectos / Tajo (Portugal, río) 


\section{UNA COLECCIÓN SINGULAR}

La Colección de Galeras Reales portuguesas está formada por seis embarcaciones que se encuentran expuestas al público en el Museo de la Marina de Lisboa. Se las conoce, normalmente, por el nombre o el cargo de quien las mandó construir, con excepción del Bergantín Real -también conocido como Galera Real-, que fue encargado en 1780 por la reina doña María I. De las otras galeras de esta colección, cuatro fueron construidas en el siglo XVIII: Galera de don Juan $V_{1}$ de don José I, de doña Carlota Joaquina y del Inspector de la Aduana de Lisboa. La sexta es ya del siglo XIX, se la llama de don Miguel I, y fue montada por orden de este monarca en 1831.

Cada una de estas embarcaciones se construyó para transportar a la familia real portuguesa y a sus homólogos europeos, en trayectos cortos por el río Tajo o desde sus naos y yates hasta tierra firme, en los viajes de Estado a la capital portuguesa. Como colección sabemos que constituye un ejemplo de Patrimonio marítimo único en el mundo; como realidad museológica posee el don de hechizar con su majestuosa presencia, con su aroma a memoria y olvido y con el encanto de sus formas erosionadas por el tiempo a todo el que se acerca a ella.

\section{Las Galeras Reales: un mar de emociones repletas de historia}

Según el estudio realizado en los últimos años, parece ser que fue durante la visita de Felipe II de Portugal (III de España) a Lisboa, iniciada el 29 de junio de 1619, cuando los portugueses tuvieron por primera vez la oportunidad de conocer de cerca un nuevo tipo de embarcación: la galera. Cuenta la historia que este monarca viajó a Portugal acompañado de su hijo Felipe III de Portugal -IV de España- con el objetivo de que este último prestase juramento ante las cortes portuguesas, lo que sucedería el día 14 de julio de ese mismo año. Manuel de Sousa nos cuenta cómo "deslocou-se a Lisboa para que o príncipe herdeiro prestasse juramento ante as Cortes portuguesas, tentando simultaneamente acalmar os descontentamentos que havia provocado a política do vice-rei (marquês de Alenquer). A entrada, preparada pelo cronista João Baptista Lavanha e o pintor Domingos Vieira Serrão, foi sumptuosa. 0 Arco dos Italianos engrandecia o rei..." (SOUSA, 2000: 112). Ante el asombro del pueblo portugués, este monarca llegó a tierras lusas acompañado de una comitiva de trece bellisimas naves, de entre las que destacaba la Galera Real que, según la bibliografia consultada "surgia, enorme, rica de talha doirada de proa a popa, com a elegância de um cisne e a nobreza de uma obra de arte" y era movida por una "chusma de quatrocentos e vinte forçados, vestidos de damasco carmesim" (GALÉS, 1970: 14). Varias décadas después, hacia 1666, se construiría el primer Bergantín Real portugués en el astillero de la conocida Ribeira das Naus, en Lisboa. En agosto de ese mismo año sería utilizado para recibir a la princesa María Francisca Isabel de Saboya.

Pasado un tiempo, en 1687, don Pedro II mandaría construir, por primera vez, un bergantín portugués con el camarín acristalado

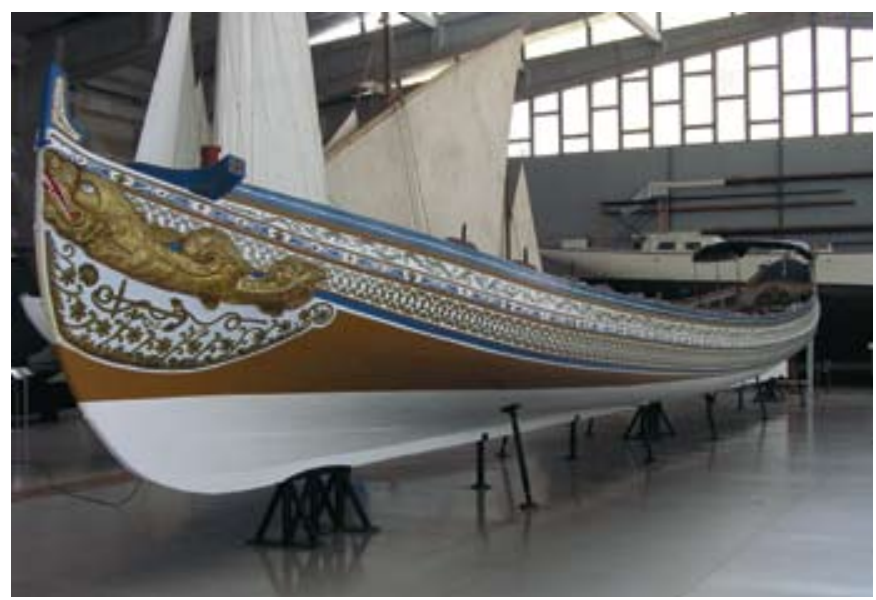

Colección de Galeras Reales Portuguesas. Galera de don Juan V (1728). Fuente: Revista da Armada, 409

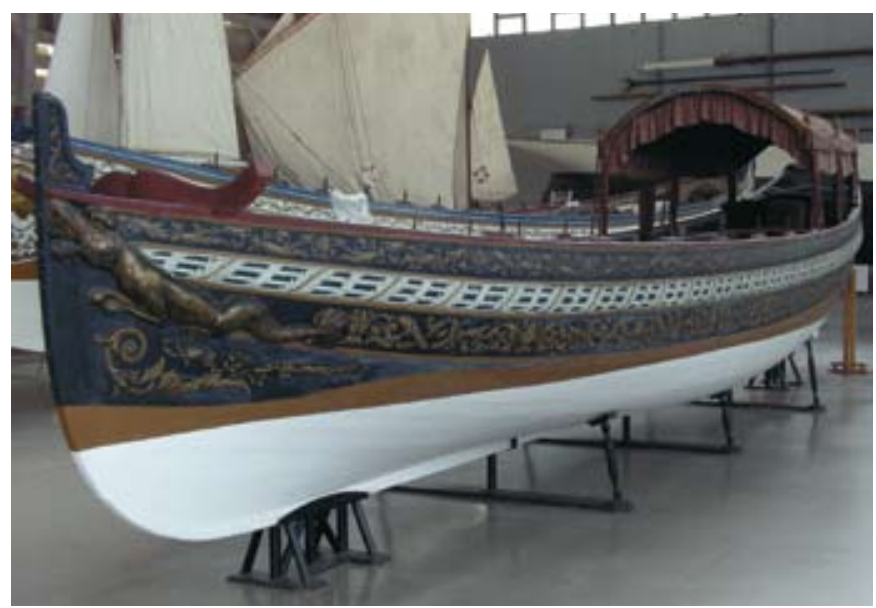

Colección de Galeras Reales Portuguesas. Galera de doña Carlota Joaquina (1790). Fuente: Revista da Armada, 409

para poder recibir adecuadamente a su segunda esposa, doña Maria Sophia Isabel de Neubourg, futura madre de don Juan V (ESPARTEIRO,1965).

En 1728, bajo unas tendencias artísticas bastante más recargadas, don Juan $\vee$ encargó una nueva embarcación real de la que se llegó a decir que "todo ele mais parecia um custoso e imperial palácio, do que bergantim" (GALÉS, 1970: 14). Esta embarcación forma parte de la colección que podemos ver actualmente en el Museo y es conocida como Galera Grande o Galera de don Juan V.

En ese mismo siglo, entre 1780 y 1783 se construiría la embarcación más importante de las seis que se encuentran actualmente en el Museo de la Marina: el único bergantín real portugués que ha sobrevivido hasta nuestros dias. Fue en realidad la reina doña María l la que le encargó la nave al ministro de marina Martinho de Melo e Castro en 1778. El motivo: la celebración de las nupcias del principe don Juan con la infanta española Carlota Joaquina y de la infanta Maria Ana Vitória con el infante español don Gabriel, que tuvieron lugar en Lisboa en mayo de 1784 (CUTILEIRO, 1998: 67).

Para la fabricación y decoración de esta galera serían seleccionados algunos de los mejores especialistas nacionales de la época y se utilizarian los materiales y técnicas más nobles hasta entonces 


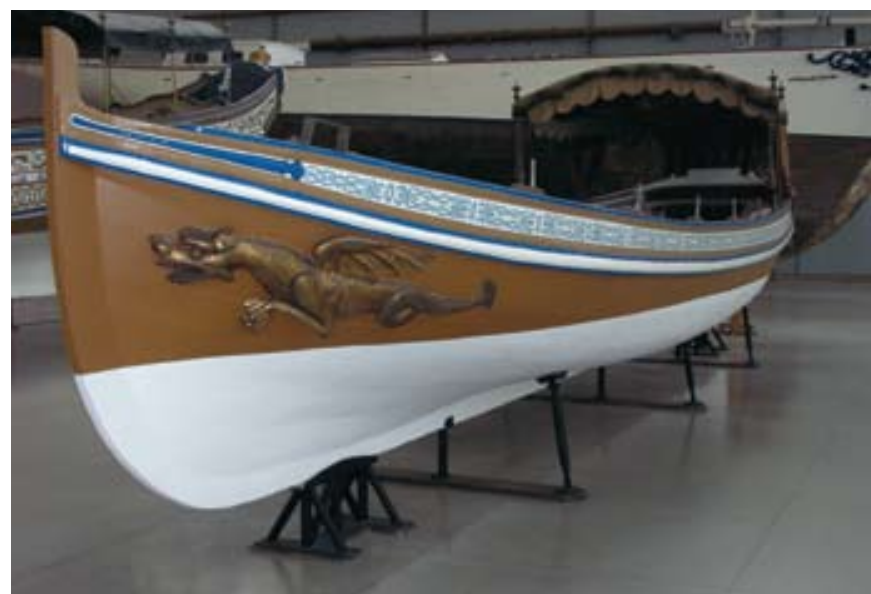

Colección de Galeras Reales Portuguesas. Galera de don Miguel I (1831). Fuente: Revista da Armada, 409

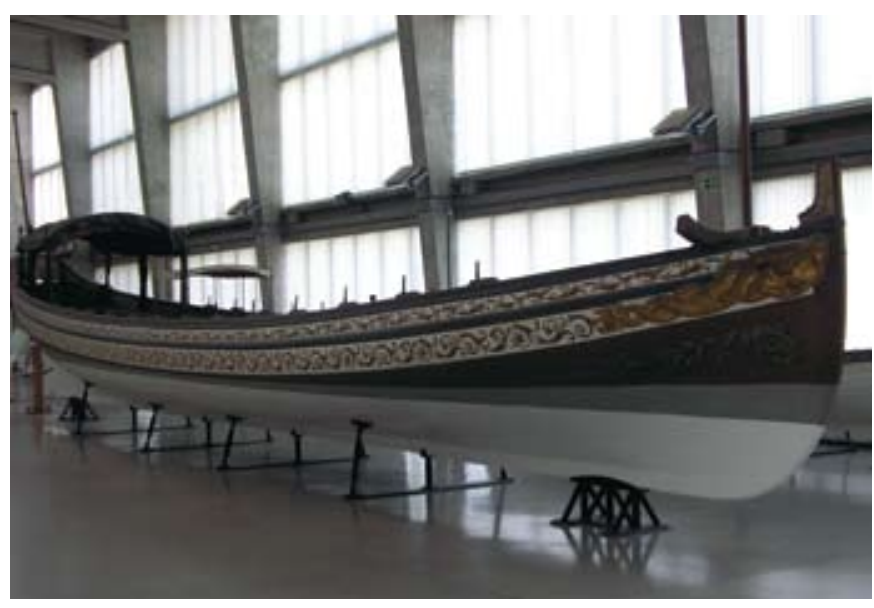

Colección de Galeras Reales Portuguesas. Galera de don José I (1753). Fuente: Revista da Armada, 409

conocidos. De entre ellos cabe destacar el oro traído de las coIonias portuguesas que serviría para revestir la totalidad de los elementos de talla que decoran el interior y el exterior de la embarcación y también los frisos decorativos que podemos observar a babor y a estribor por encima de la línea de flotación.

Algo semejante, aunque a menor escala, sucedería con las galeras de don Juan V, don José I, doña Carlota Joaquina y don Miguel. La del inspector de la aduana de Lisboa sería construida con un objetivo diferente, acompañar al séquito real en sus desplazamientos, lo que acabaría por traducirse en una decoración mucho más sencilla, como podemos observar en las imágenes que ilustran esta sección.

Desde 1783 hasta 1908 -fecha en la que el asesinato del rey don Carlos provocaria prematuramente el final de un largo periodo monárquico- estas embarcaciones estuvieron al servicio de la corte portuguesa. En 1957, el Bergantín Real sería utilizado una última vez con su función original, con motivo de la visita de la reina Isabel de Inglaterra.

Como embarcaciones reales, las galeras transportaron por el río Tajo, hasta el Cais das Colunas, en el Terreiro do Paço -actual Praça do Comércio- a numerosas personalidades de la Europa

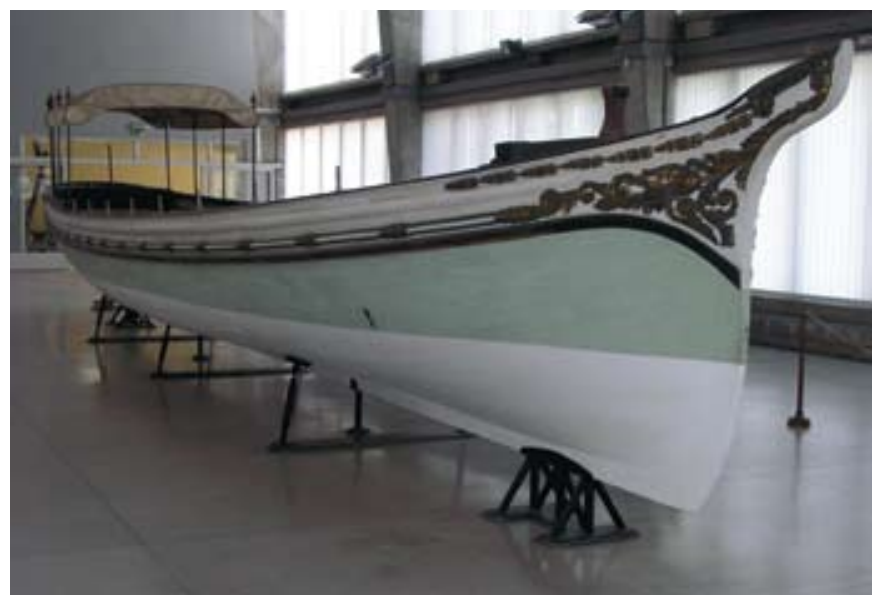

Colección de Galeras Reales Portuguesas. Galera del Inspector de la Aduana de Lisboa (1768). Fuente: Revista da Armada, 409

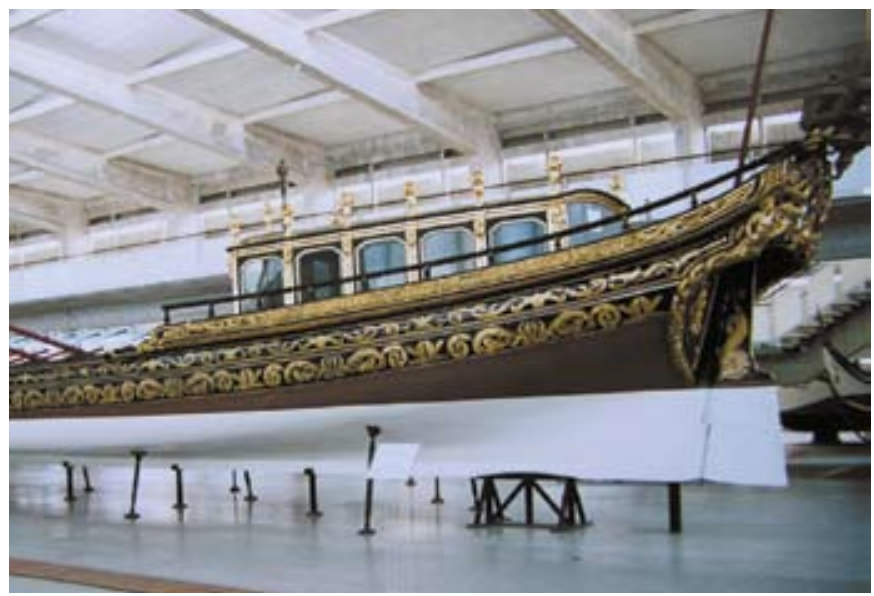

Colección de Galeras Reales Portuguesas. Bergantín Real (1780). Fuente: Revista da Armada, 409

contemporánea. Entre ellas destacan, de Portugal, la reina doña Maria II y el rey don Fernando; el rey don Luís -también conocido como el rey marinero-; doña Maria Pía de Saboya -que visitaría Portugal en octubre de 1862-; la reina doña Amelia, el rey don Carlos -asesinado en 1908 junto a su hijo mayor el principe Luis Filipe-; el infante don Alfonso y también los famosos aviadores Gago Coutinho e Sacadura Cabral, protagonistas de la primera travesía aérea por el Atlántico, que tendria lugar entre las ciudades de Lisboa y Río de Janeiro en 1922.

De España podemos destacar a la reina $\mathrm{M}^{\mathrm{a}}$ Cristina, que visitó Portugal en 1836; a la reina Isabel II que junto con su marido e hijos, sería invitada por el rey don Luis a una regata por el río Tajo a bordo de las "falúas reales" el 13 de diciembre de 1866. De ella se cuenta que, antes de partir para su pais de origen, realizó un conjunto de donativos en agradecimiento a la excelencia de los servicios prestados, destacándose entre ellos el que guarda relación con la experiencia vivida a bordo de las galeras, pues tal y como refiere un texto de la época "S.M. la reina mandó regalar espléndidamente a los remadores de las Falúas Reales" (VIAJE, 1867 : 201). Por último, navegarian también en estas embarcaciones los reyes Alfonso XII y Alfonso XIII, siendo este último recibido por el Bergantín Real en su visita a Portugal el 14 de diciembre de 1903. Sabemos además que este monarca solía reunirse con don Carlos 


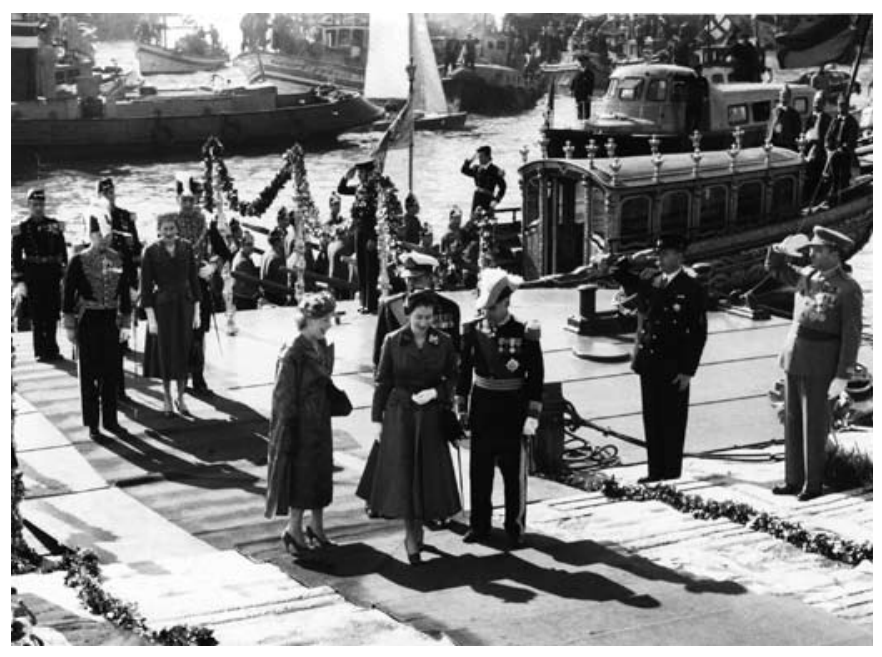

Recepción de Isabel II de Inglaterra a su llegada a Lisboa en 1957 por el general Craveiro Lopes. Fuente: Revista da Armada, 406

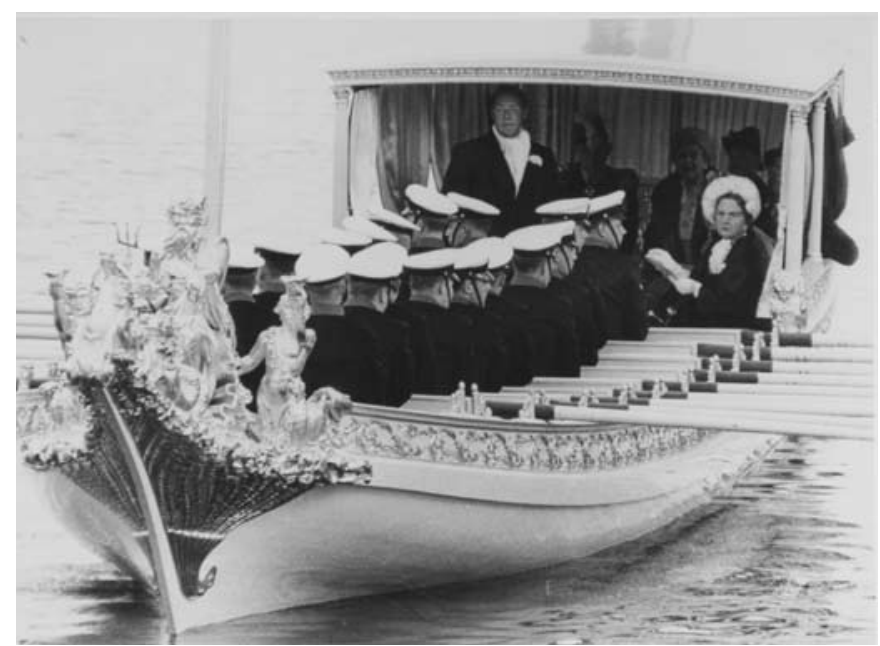

La reina Juliana en 1962, en el último paseo realizado por la Galera Real Holandesa, en el río Amstel. Fuente: Colección del M. N. de la Marina de Ámsterdam

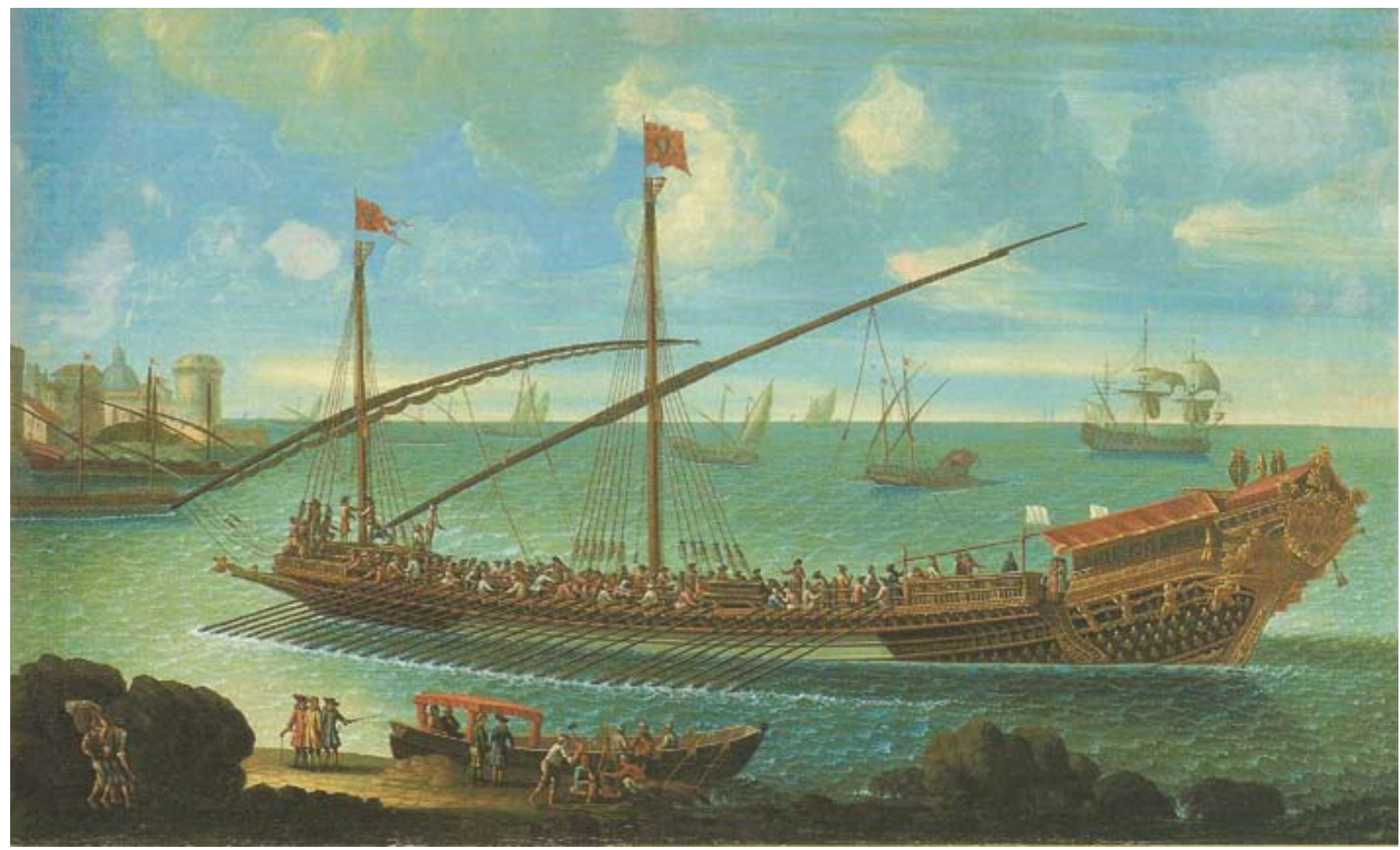

Pintura al óleo donde aparece representada La Réale (anónimo, 1694). Museo de la Marina de París. Fuente: Les Génies de la Mer

y con sus hijos en el Palacio de Vila Viçosa, con el fin de celebrar jornadas cinegéticas'.

Pero no sólo personalidades portuguesas y españolas pasearían por el Tajo en estas naves; también lo harian el presidente de la República francesa Emile Loubet en 1905, o miembros de la familia real inglesa como la reina Adelaida, Eduardo VII -que escogería Portugal como destino para su primera visita de Estado en abril de 1903- y dos años después la reina Alexandra.

Asimismo las utilizaron importantes personajes alemanes, como el Emperador Guillermo II, que llegaría a Portugal en marzo de 1905 para visitar al Regimiento de Caballería 4 -del que sería nombrado coronel honorario por el rey don Carlos-, el rey Frederico de Saxe que visitaria Portugal a título privado, en marzo de 1907, y doña Estefania de Hohenzollern-Sigmaringen, entre otros.

En febrero de 1957, el Bergantín Real volveria a desfilar por el río Tajo en la que sería su última misión real, la recepción de la reina Isabel II de Inglaterra en su llegada a Lisboa.

Estudio comparativo: otras colecciones de galeras reales del siglo XVIII en el panorama museológico internacional

Hace aproximadamente dos años inicié una investigación con el objetivo de conocer otras embarcaciones reales de estas características o similares, en otros lugares de Portugal y también en el resto del mundo. El perfil buscado se ajustó al de las naos origi- 


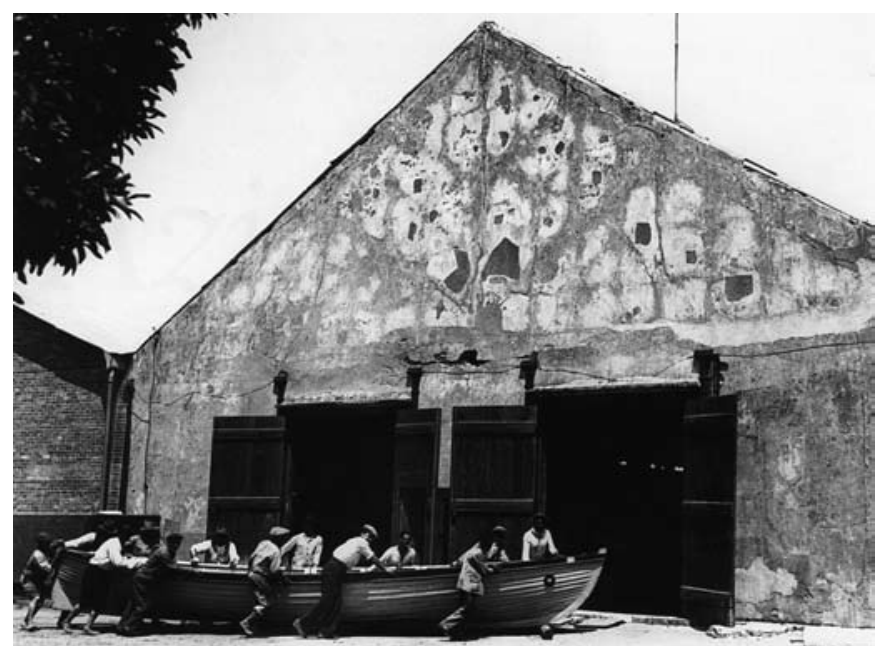

Pabellón de las Galeras Reales de Azinheira en el año 1934 Fuente: Azinheira: Espaço e Tempo, 2007

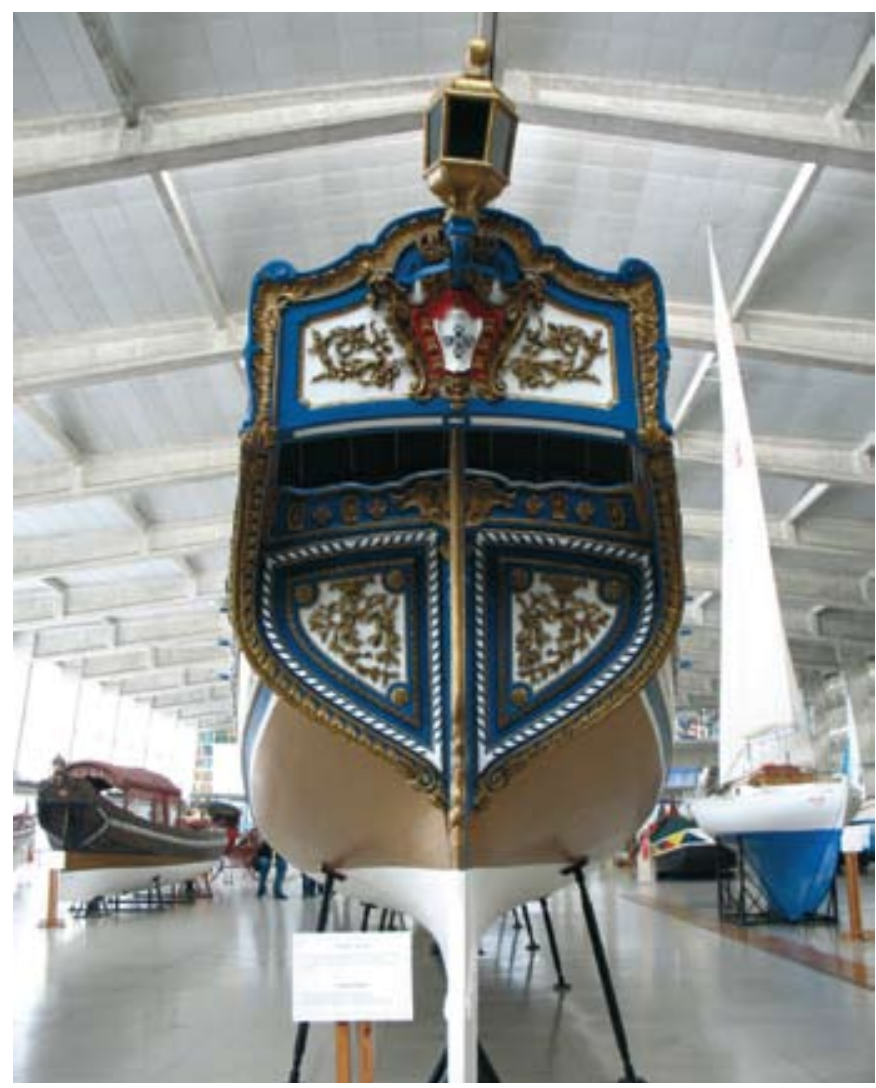

Popa de la Galera de don Juan V. Foto: Marcela Tavares. Fuente: www.flickr.com/ photos/capitu/

nales, construidas en contexto y función real entre los siglos XVII y XIX; tenía también esta investigación un objetivo práctico, el de utilizar la información recogida como uno de los argumentos fundamentales que permita la futura clasificación de esta colección como bien de interés nacional -también conocidos en territorio portugués como "tesoros nacionales"-

Según la Ley no 107/2001 de 8 de septiembre que "establece las bases de la política y del régimen de protección y valorización del patrimonio cultural", son bienes culturales, muebles o inmuebles, todos aquellos que "siendo testimonios con valor de civilización o de cultura portadores de interés cultural relevante, deban ser objeto de especial protección y valorización" (Título I, artículo 2º). Además, un bien inmueble se considera de interés nacional "cuando su pro- tección y valorización, en todo o en parte, represente un valor cultural significativo para la nación" (Título IV, artículo 150-4). Pues bien, estábamos ante uno de estos casos, sin lugar a dudas, no sólo por el carácter de esta colección o su interés como testimonio notable de vivencias y hechos históricos, sino también por los valores estético, técnico y material que presenta, y por la importancia de este conjunto como reflejo de la memoria colectiva y como fuente documental insustituible para la investigación histórica (Título IV, artículo 17º).

Por otro lado, es evidente que esta clasificación constituye fundamentalmente un acto político. Lo que nos mueve a avanzar en esta dirección no es sólo el hecho de saber que se trata de una medida apropiada para una colección como ésta. Sabemos también que este paso supone la adquisición de un valioso instrumento educativo para la ciudadanía (RAPOSO, 2007), que trae consigo un conjunto de herramientas extremadamente útiles a la hora de dinamizar una colección de esta naturaleza, una colección de la que todavía queda mucho por descubrir.

Pues bien, a lo largo de los últimos meses, hemos podido confirmar nuestra sospecha sobre la auténtica relevancia de este conjunto de embarcaciones: se trata de una colección única en el mundo, tanto por su naturaleza y por sus características artísticas, históricas y técnicas, como porque además no existe ninguna otra colección de embarcaciones reales originales y datadas en el siglo XVIII que se encuentre completa en la actualidad.

Hemos encontrado casos muy interesantes en el Museo de las Falúas Reales del Real Sitio de Aranjuez, donde existen un total de cinco originales de entre las que se destaca la Falúa de Felipe $V$, construida en el segundo tercio del siglo XVIII; la Canoa Imperial de Napoleón I que, junto a la ornamentación de popa de la Galera Real y a la proa de la Canoa de Paseo de la reina Marie-Antoinette, se encuentra en el Museo de la Marina de Paris; la Koningssloep o Galera Real, conservada en el Museo Maritimo de Ámsterdam y que fue construida entre 1816 y 1818, y otras piezas importantes que se encuentran en el Museo Marítimo de Greenwich, en el Museo Naval de Estambul o bajo la responsabilidad del Ayuntamiento de Venecia. Sin embargo, en ninguno de estos casos las embarcaciones responden al perfil de la colección portuguesa pues, o la colección no se encuentra completa o su fecha de construcción se localiza en el siglo XX -siendo en la mayoría de los casos réplicas de antiguas embarcaciones construidas en los siglos XVII, XVIII y XIX-, o se trata de embarcaciones individuales que nunca llegaron a formar parte de una colección con carga histórica y artística propia.

\section{EL PROYECTO DE CONSERVACIÓN}

\section{Investigación histórica sobre las intervenciones del pasado}

En la Biblioteca del Museo de la Marina y en la Biblioteca Central de la Marina, he podido acceder a un conjunto de documentos sobre los artistas que en su momento fueron escogidos para la realización 
de los elementos decorativos del interior y del exterior de las dos galeras más importantes: el Bergantín Real y la galera de don Juan V. Sin embargo, no he podido encontrar nada sobre los materiales o las técnicas utilizados por estos artistas, o sobre las intervenciones de restauración realizadas hasta mediados del siglo XX.

Sabemos que la colección de galeras reales se mantuvo activa hasta la implantación de la República (en 1910) y que, como símbolo por excelencia de la realeza portuguesa, a partir de ese momento hasta su entrada en el Museo de la Marina, se guardó en el Depósito de Azinheira que se encuentra en la orilla izquierda del río Tajo en la zona de Seixal, a unos $15 \mathrm{~km}$. de Lisboa. A lo largo de todas estas décadas sólo salieron de su depósito por motivos muy especiales, como lo fue, en su momento, la visita de la reina Isabel II de Inglaterra a Portugal.

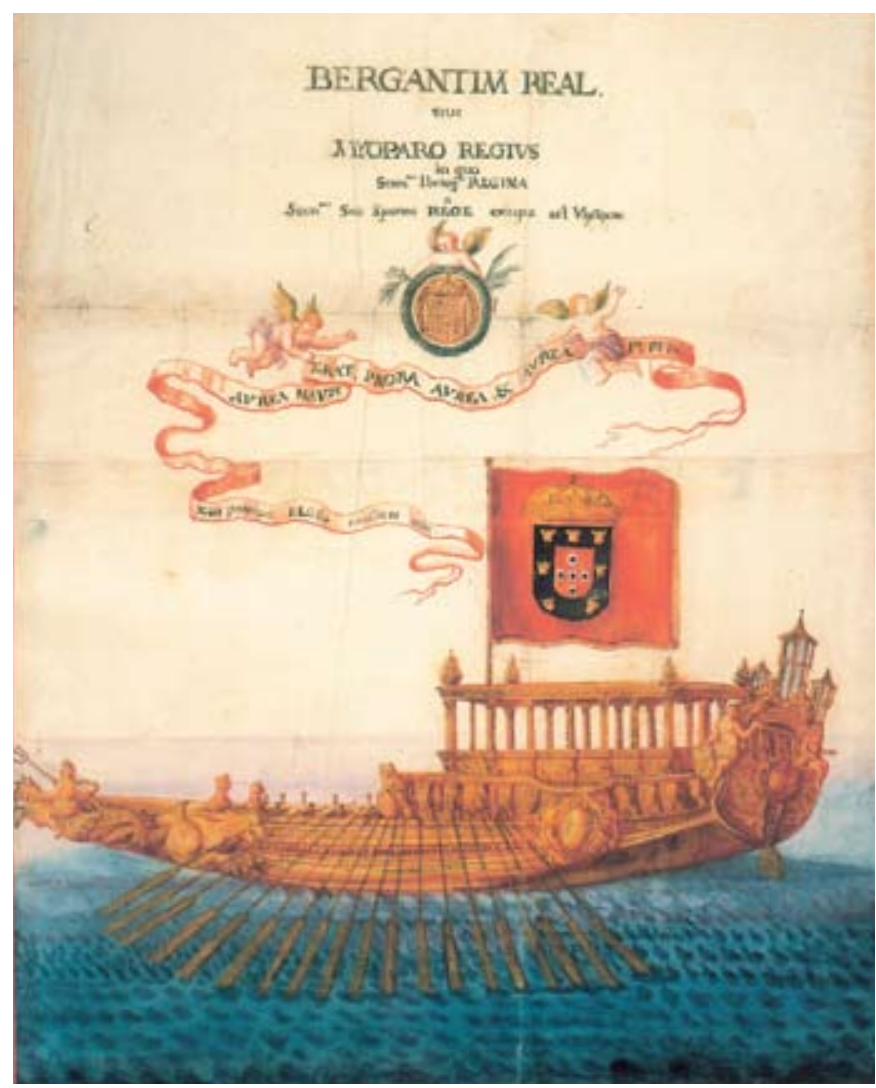

Grabado de época representando el Bergantín Real construido para doña Sofía de Neubourg en 1687. Fuente: Revista da Armada, 405

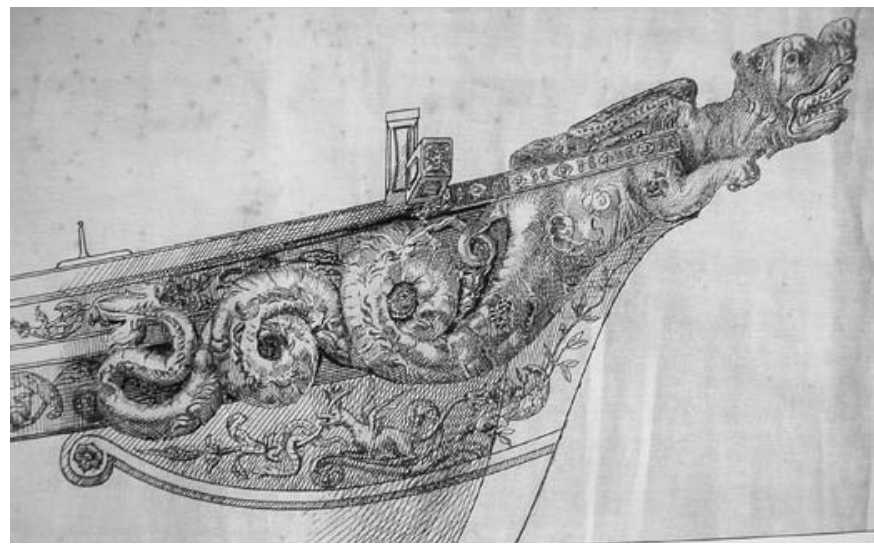

Figura de proa del Bergantín Real de doña María I. Diseño original en tinta china sobre papel. Fuente: Revista da Armada, 410
No obstante, la investigación realizada nos demuestra que, debido sobre todo a la función que desempeñaron hasta ser transportadas al Museo en 1962, esta colección fue objeto de frecuentes intervenciones de restauración a lo largo de sus más de 200 años.

Tenemos dos pistas para caminar por esa historia: el análisis de las imágenes que han sobrevivido hasta hoy, en las que podemos comprobar los cambios que, por razones de moda, ideología o creencia fueron realizados a lo largo de los varios mandatos reales que se sucedieron al de la reina doña Maria l; y el análisis de los estratos que componen cada una de las obras que decoran estas embarcaciones, mediante la aplicación de las diversas técnicas que se utilizan actualmente en el área de la ciencia de los materiales.

Del primer caso encontramos un buen ejemplo en la decoración

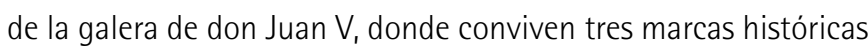
pertenecientes a tres reinados diferentes: la primera se encuentra situada en la tela a óleo que cubre el baldaquín del camerino real. En ella observamos una composición donde aparecen representadas, en primer plano, las armas del reino de don Juan $\mathrm{V}$ (hacia 1720); la segunda composición decora el panel de la popa y representa las armas y el escudo de la reina doña Maria I (hacia 1780); la última se encuentra en el espaldar del banco principal del camarín real, y se trata de una composición en la que podemos observar el escudo de armas de don Pedro V (hacia 1855).

Del segundo caso expondré más adelante un ejemplo en el apartado dedicado a la intervención realizada en el Bergantín Real: los resultados de los análisis estratigráficos realizados en la obra pictórica que decora la pared posterior de la segunda sala del camarín real.

Continuando con nuestro paseo por la historia, el 18 de febrero de 1957 el Bergantín Real iría a recibir a la reina Isabel II de Inglaterra a su yate real, el Britannia, que se encontraba anclado en medio del río Tajo. Esta sería la última misión del Bergantín para la corona portuguesa. Para este acontecimiento la embarcación sería objeto de una profunda reforma estética. Quién la hizo y cómo la hizo son preguntas para las que no hemos hallado respuesta directa; apenas hemos podido comprobar mediante análisis, que los materiales utilizados no eran de la misma naturaleza que los que decoraban originalmente la embarcación, sino imitaciones cuya adquisición y aplicación no exigía necesariamente ni un elevado presupuesto ni la presencia de especialistas. Según la dirección del Museo, es muy probable que los autores hayan sido los propios maestros del arsenal de la Marina portuguesa.

El 15 de agosto de 1962 el Museo de la Marina inaugura sus nuevas instalaciones en la zona de Belém, junto al Monasterio de los Jerónimos. De hecho, ocupará el lateral izquierdo del propio edificio monacal, así como otro edificio, de corte modernista, que se construiría adosado al anterior. El nuevo Museo obedece a una concepción de uso múltiple: además de una zona dedicada a las secciones técnica y administrativa, en cuyo piso superior sería colocado posterior- 


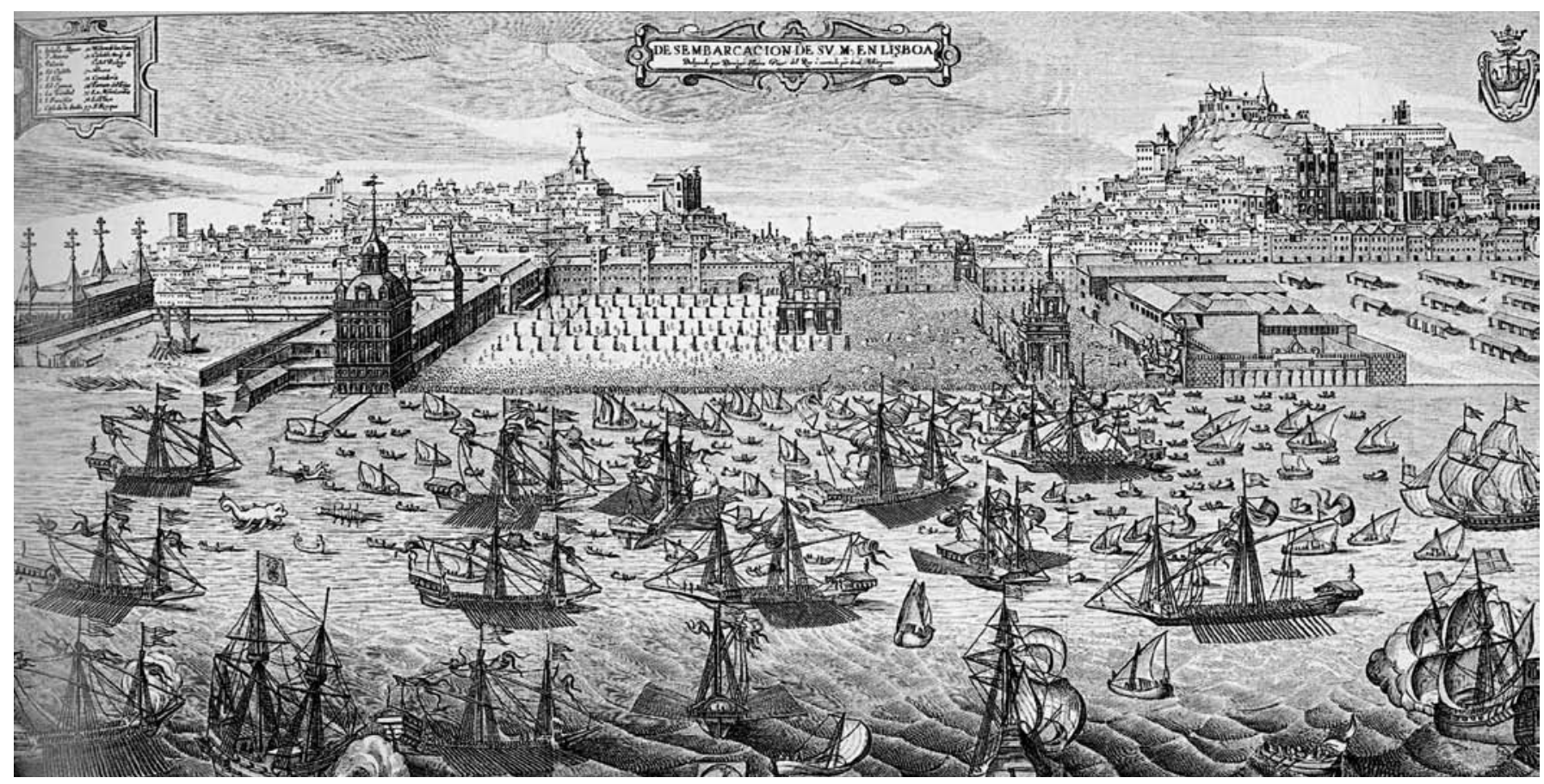

Grabado de la época que refleja la llegada a Lisboa de Felipe II de Portugal (III de España) en junio de 1619. Fuente: Revista da Armada, 405

mente un Planetario, fue construido un pabellón con la finalidad exclusiva de exponer en él la colección de Galeras Reales.

Tras un largo letargo las galeras iniciaban una nueva fase vital, les aguardaba una vida social intensa y un lugar fundamental en el contexto de un Museo cuya misión sería establecer una plataforma de comunicación que permitiese divulgar la historia marítima del pueblo portugués.

Con motivo de la inauguración del Museo las Galeras Reales volverian por última vez a su medio natural, el acuático, con el objetivo de llegar hasta las nuevas instalaciones. Pocos días después, y durante los meses de junio y julio, se llevaría a cabo una profunda intervención de restauración en esta colección.

En 1974, y ante el pésimo estado de conservación que presentaban las embarcaciones expuestas, se realizaron un conjunto de intervenciones puntuales destinadas a estabilizar los procesos de deterioro más avanzados y que constituian una amenaza física para la integridad de algunos de los elementos de esta colección². Fueron así sustituidos todos los travesaños deteriorados de la estructura de la galera de doña Carlota Joaquina y de la galera del Inspector de la Aduana de Lisboa y, en el Bergantín Real y en la galera de don Juan $\mathrm{V}$, fueron sustituidos los materiales utilizados originalmente en el calafateado por tiras de pino de albar, con el objetivo de evitar futuros desprendimientos de la capa pictórica que decoraba el exterior (CUTILEIRO, 1998: 139-141).

En la década siguiente, ya en 1987, sería contratado nuevamente el mismo pintor naval que realizara la intervención de 1974, el señor Luis Teixeira, para "refazer integralmente a decoração exterior do Bergantim Real ${ }^{3 " .}$ Según declaraciones de este mismo especialista, la galera se encontraba en un estado de deterioro avanzado, por lo que optó por documentar los fragmentos de los frisos decorativos que todavía se encontraban legibles y, posteriormente, eliminó cualquier indicio de decoración hasta entonces existente con la ayuda de un soplete. De acuerdo con este modelo de trabajo, entre 1987 y 1991 reproduciria la decoración exterior de los laterales de la embarcación, tomando como referencia la documentación que el propio pintor había realizado.

Cuando Luis Teixeira nos refirió que el panorama que encontró en 1987 en el pabellón de las galeras reales era desolador, se refería, evidentemente, a un estado de conservación lamentable; como es lógico, si a una colección de embarcaciones originales del siglo XVIII, que durante casi 200 años se mantuvo activa -lo que irá indudablemente acompañado de un proceso natural de envejecimiento de los materiales y de todo un conjunto de manipulaciones, adaptaciones y otras alteraciones causadas por las propias personas- la retiramos de un día para otro de su medio natural, el agua, se producirán toda una serie de consecuencias, de mayor o menor alcance, hasta que consigan adaptarse a su nuevo medio, el terrestre, si es que algo así puede llegar a suceder algún día.

A esto debemos añadir que el pabellón que fue construido en 1962 para albergar esta colección constituyó en su momento todo un desafio arquitectónico por su carácter innovador; sin embargo, desde el punto de vista de la conservación, tan sólo podemos decir que es comparable a un invernadero donde en verano se llegan a alcanzar los $40^{\circ} \mathrm{C}$ y donde la humedad relativa -que en diciembre sube al 90\%- es capaz de descender hasta el $40 \%$.

El día 20 de noviembre de 1997 se le atribuye al Bergantín Real el World Ship Trust International Maritime Heritage Award ${ }^{4}$. Entretanto, en el Museo, la salud de las embarcaciones reales empeora cada día ante la ausencia de un mínimo plan de conservación. Las galeras, en otros tiempos auténticas estrellas, languidecen en un 
pabellón en el que, entretanto, van colocándose otras embarcaciones más relacionadas con la construcción naval tradicional.

Iniciado el presente milenio, la dirección del Museo, comprendiendo la pérdida que suponía para la historia marítima portuguesa el deterioro constante, progresivo e irreversible de una colección de estas características, encargó un proyecto de investigación y documentación, destinado a la restauración del Bergantín Real. El encargo recayó en un equipo compuesto por Simona Franchin, Ana Raquel Leitão, Silvia Márques, Patricia Pereira y Luís Filipe Monteiro que, bajo mi dirección, inició los trabajos en octubre de 2001.

El objetivo de nuestro equipo sería realizar una labor de investigación y documentación destinada a diseñar una intervención de restauración apropiada y acorde a las necesidades detectadas en la colección desde el punto de vista de la moderna metodología de la conservación. Simultáneamente, y aunque de una forma progresiva e integrada en el contexto que nos ocupa, pretendiamos llevar a la práctica una pequeña cirugía conceptual (CHAGAS, 2007), estudiando las diferentes formas de comunicación que podrian ser utilizadas para dar voz a esta importante colección de embarcaciones reales.

A finales del 2001, con el apoyo de la dirección del Museo, y conscientes ambas partes de que una intervención de conservación y restauración, adecuadamente estudiada y divulgada, permitiría la plena fruición de este Patrimonio maritimo, se inician los primeros trabajos de restauración del Bergantín Real.

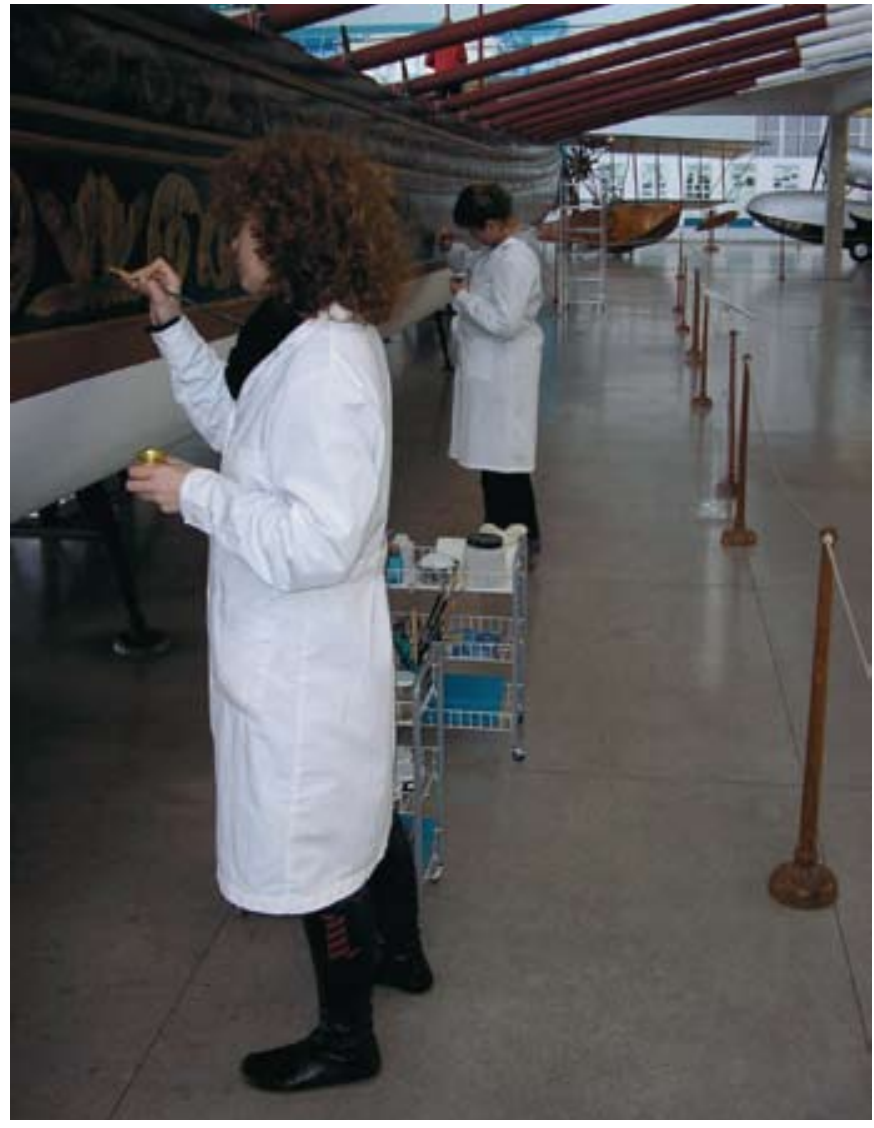

Restauración de los frisos decorativos de babor del Bergantín Real en diciembre de 2001. Foto: Lorena Sancho Querol

\section{El PCGR, un proyecto innovador en un contexto formal}

En septiembre de 2001 tendría lugar un primer contacto con el director del Museo. A lo largo de este encuentro y de los siguientes, y a través de la investigación que se inició para dar forma a lo que sería el primer proyecto de restauración, fue posible saber la razón por la que esta colección se encontraba en tan mal estado. Sencillamente, el cuadro de funcionarios del museo estaba formado, en su mayoría, por militares y, lógicamente, entre ellos no había conservadores, ni tampoco museólogos. Apenas existían en los talleres del Museo un equipo de especialistas en construcción naval de modelos que incluia modeladores, ebanistas y pintores.

El hecho de ser un Museo militar desde sus orígenes se manifestaba en forma de discurso cerrado y a través de una museografía tradicional que, en algunos casos, revelaba una actitud cuando menos poco cuidadosa para muchos de los bienes culturales expuestos al público.

Estaba claro que el Museo de la Marina de Lisboa poseía una de las colecciones de patrimonio marítimo más importantes del mundo, y como prueba de ello no sólo estaban las Galeras Reales, sino también otras colecciones, como la de astrolabios, de consideración internacional ${ }^{5}$. Sin embargo parecía haber olvidado su vocación de mediador cultural, de lugar fundamental para acceder a la dimensión patrimonial de nuestra educación (HOMS 2004: 40).

En ese contexto, la dirección del Museo mostró interés en apoyar el Proyecto de Conservación de las Galeras Reales portuguesas, sin duda consciente de su responsabilidad ante el estado de conservación de la misma embarcación que cuatro años antes recibiera el World Ship Trust International Maritime Heritage Award. Nuestra misión, por lo tanto, según el director, debía comenzar por la restauración del exterior del Bergantín Real.

En la primavera del año 2002 presentamos un Proyecto de Restauración específico para esta embarcación, pero no sólo para su parte exterior, sino para toda ella, mediante una serie de fases organizadas de tal modo que la ejecución de cada una nunca supusiese una inversión económica elevada para el Museo. El equipo era consciente de que el esfuerzo realizado carecería de sentido si no se planteaba desde una perspectiva de conjunto que permitiera posteriormente dar forma a un proyecto de conservación para toda la colección de embarcaciones. Además, había otros objetivos subyacentes a esta iniciativa, objetivos entre los que se encontraban la investigación y la difusión del patrimonio marítimo en juego.

Entre octubre de 2002 y febrero de 2003 se llevaría a cabo la restauración del exterior del Bergantín o Galera Real para lo que, previamente, solicitamos a la dirección del Museo que nos pusiese en contacto con un ingeniero naval que pudiese realizar un examen de la estructura de la embarcación; durante el siguiente año, conforme iban siendo puestos a nuestra disposición los medios 
solicitados para la ejecución de cada fase, fuimos efectuando la restauración de los demás elementos decorativos de la nave.

Poco a poco se fue creando una plataforma de entendimiento que permitiria que lo que había empezado como una intervención puntual se transformara en una acción regular y constante; las dos caras de esta plataforma eran: el director del Museo, un capitán de Mar y Guerra con interés, sensibilidad, un pequeño presupuesto variable de un año para otro y un reglamento específico y riguroso; y un joven equipo de especialistas en restauración y conservación -formado por cinco mujeres y un hombre- que habian aceptado el desafío de organizar lo que con tiempo, paciencia, compresión y sobre todo, mucho empeño, se transformaría en el Núcleo de Conservación del Museo de la Marina.

En octubre del 2004, cuando la restauración del Bergantín Real estaba llegando a su fin, tuvo lugar una nueva reunión con la dirección con el objetivo de presentarle un proyecto más amplio, que respondiera a las necesidades detectadas en esta importante colección de embarcaciones durante los años de trabajo transcurridos. El trabajo realizado debía de constituir lo que llamaríamos la I Fase del Proyecto de Conservación de las Galeras Reales, que estaria formado por seis fases, una para la restauración de cada una de las embarcaciones.

Además, pretendiamos trabajar con esta colección uniendo dos áreas de especialización que siempre debieron caminar de la mano en un contexto cultural como éste: la conservación y la museología. El discurso tendria a partir de ese momento una intensidad y un tono diferentes a los practicados por el Museo hasta aquel entonces. La idea principal consistía en comprender el objeto como resultado de las relaciones sociales que lo habian producido (SANTOS, 1999).

Por suerte para el equipo, tanto en portugués como en español el término "conservación" es lo suficientemente amplio como para albergar en su interior los trabajos de investigación y de documentación, así como los de intervención, tanto en los bienes expuestos como en su entorno, desde una perspectiva diversificada y abierta a la reflexión a nivel interno y externo, al equipo y al Museo. Además no queriamos olvidar que la cuestión fundamental no es que el pasado ya haya pasado, sino la forma en que, desde el presente y con los procedimientos del presente, entendemos o damos a entender ese pasado (FREIRE, 2000: 75)

\section{LAS CARACTERÍSTICAS TÉCNICAS Y LOS OBJETIVOS DEL PROYECTO}

\section{La organización de la colección}

En 2001 la colección de Galeras Reales se encontraba simplemente inventariada como $\mathrm{OE}$, es decir como originales de embarcaciones integrados en el contexto de la colección del Museo. El número que acompañaba a este código indicaba, en principio, el orden de entrada de las piezas en el museo en 1962. Por ejemplo, el Bergantín Real era el $\mathrm{OE}-7$ y la galera de don Juan $\mathrm{V}$ era el $\mathrm{OE}-11$; es decir, no existía una lógica aparente que, mediante la aplicación de un conjunto de criterios, hubiese permitido el inventario adecuado de una colección de estas características.

Así, aunque la Ley Marco de los Museos portugueses (Ley 47/2004) establece que todos los bienes culturales incorporados a un museo deben ser objeto de inventario museológico, siendo éste la relación exhaustiva de los bienes que constituyen el fondo propio de cada museo (Arts. 15 a 20), en el Museo de la Marina, el conjunto de obras que decoraban el interior y el exterior de cada una de las galeras no se encontraba inventariado ni poseía un código que permitiese su identificación y localización. No existía registro alguno de intervenciones de conservación y restauración realizadas en la colección desde su entrada en el Museo, ni de las condiciones ambientales en las que esta colección intentaba sobrevivir día tras dia. Evidentemente, tampoco existía un plan de conservación que permitiese una actuación regular en cada una de las embarcaciones, según las situaciones identificadas y su evolución a lo largo del tiempo.

Nuestro equipo comprendió que, aunque no se trataba de la selva amazónica, sí nos encontrábamos ante un bosque patrimonial con una vegetación tupida, tan tupida como para obligarnos a iniciar un proceso exhaustivo de documentación de cada una de las especies que alli habitaban, de sus origenes, denominaciones, comportamientos, funciones e incluso de su historia o, mejor dicho, de los ingredientes de su historia, hasta entonces desconocidos.

Tras un primer estudio decidimos que lo más adecuado sería diseñar una estructura de trabajo que nos permitiria, mediante la aplicación de un conjunto de tres criterios técnicos, inventariar correctamente la totalidad de la colección, organizar las embarcaciones por orden de importancia y, por último, decidir cuál sería el orden de los trabajos en cada una de las fases del proyecto, es decir, en el proceso de restauración de cada una de las embarcaciones. Estos criterios serian:

1. La creación de un nuevo código que permitiera el inventario adecuado de las embarcaciones y de todos sus elementos, decorativos o no. Este código guardaría relación con el método utilizado por el Museo para este efecto, por una cuestión de lógica organizativa. La sigla elegida sería ERO: Embarcaciones Reales Originales.

2. La numeración de las embarcaciones por orden de importancia según los valores histórico, artístico y técnico presentados en cada caso. Según este criterio serian organizadas de la siguiente manera:

- No1 Bergantín Real.

- No2 Galera de don Juan V.

- No3 Galera de don José I.

- N4 Galera de doña Carlota Joaquina.

- No5 Galera de don Miguel.

- N6 Galera del Inspector de la Aduana de Lisboa. 
3. El conjunto de bienes relacionados con cada una de las galeras sería igualmente inventariado mediante la utilización de una subnumeración que tomaría como punto de partida el código de inventario de la embarcación, seguido de un segundo dígito que responderia a la organización de los elementos siguiendo siempre el orden de fuera hacia dentro; de popa hacia proa y de abajo hacia arriba. Como ejemplo presentamos a continuación los nuevos códigos de inventario de los elementos de la Galera de don Juan V:

\section{ERO - 2 : GALERA DE DON JUAN V.}

ERO - 2-1: Panel de popa.

ERO - 2-2: Pintura de popa.

ERO - 2- 3: Linterna (panel de popa).

ERO - 2- 4: Frisos decorativos exteriores (laterales de la embarcación).

ERO - 2- 5: Figura de proa (incluye composición situada en la zona inferior de la figura de proa).

ERO - 2- 6: Escalera de acceso al camarin real.

ERO - 2- 7: Conjunto formado por 1 alfombra y 4 banquetas (decoran el interior del camarin real).

ERO - 2- 8: Pinturas decorativas de los bancos del camarín.

ERO - 2- 9: Conjunto formado por 3 cojines en damasco granate (decoran los bancos del camarin real).

ERO - 2- 10: Baldaquín del camarín real.

ERO - 2- 11: Conjunto de 6 pináculos en talla dorada

(decoran los extremos del referido baldaquín).

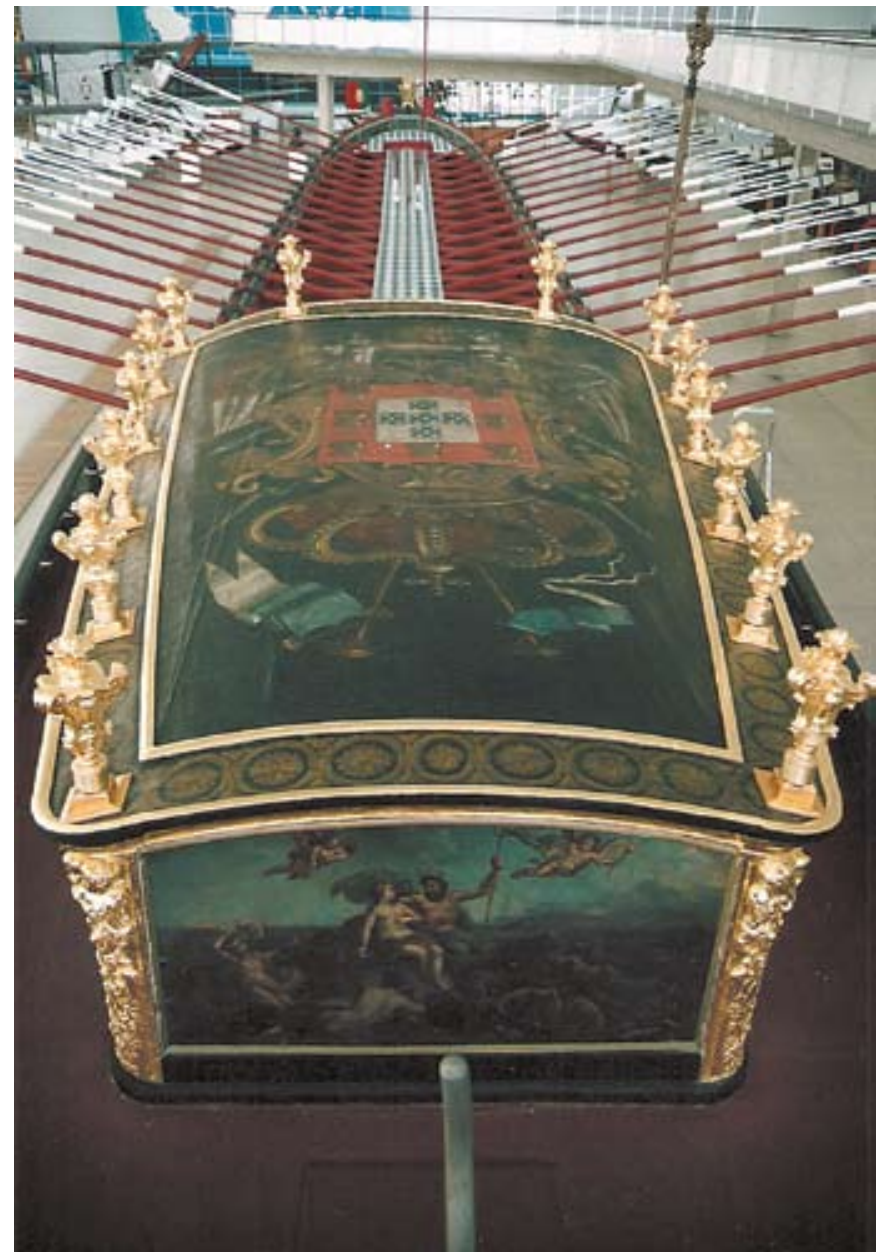

Cubierta del camarín real representando el escudo de armas de la monarquía portuguesa, tras la intervención. Foto: Lorena Sancho Querol
ERO - 2- 12: Vara del estandarte real.

ERO - 2- 13: Frisos decorativos (interior de la embarcación).

ERO - 2- 14: Conjunto formado por 40 remos.

De acuerdo con este inventario inicial, aplicado a todas las naves, se calculó la duración del proyecto de restauración en once años, estableciéndose un cronograma en función de los medios disponibles por el Museo. Sería posible trabajar a un ritmo medio de dos años para cada una de las fases del proyecto con excepción de las dos últimas. En este caso, y dada la sencillez que caracterizaba la decoración tanto exterior como interior de las embarcaciones, apenas sería necesario un año para cada una de ellas. La organización final quedaría así:

I FASE: Tuvo lugar entre octubre de 2001 y diciembre de 2004, siendo el objetivo principal la restauración del Bergantín Real.

II FASE: Tuvo lugar entre enero de 2005 y diciembre de 2006 con la finalidad de restaurar la Galera de don Juan V. Para esta fase, la dirección del Museo aprobó una idea innovadora: la creación de una estructura fija de trabajo que, a lo largo de estos dos años constituiría el germen de un futuro Núcleo de Conservación del Museo, dando simultáneamente respuesta a otras necesidades del Museo en lo que a la conservación de sus colecciones se refiere. Fue una experiencia fructífera que sirvió para demostrar a la dirección del Museo cuál era la opción más productiva desde todos los puntos de vista.

III FASE: 2007-2008. Restauración de la Galera de don José I.

IV FASE: 2009-2010. Restauración de la Galera de doña Carlota Joaquina.

V FASE: 2011. Restauración de la Galera de don Miguel.

VI FASE: 2012. Restauración de la Galera del Inspector de la Aduana de Lisboa

En el año 2007, cuando nos disponíamos a iniciar la III Fase, el proyecto se interrumpió por falta de fondos. Pocos meses después la restauración de la galera de D. José I fue llevada a cabo, desde luego con unos presupuestos mucho menos ambiciosos, por otro equipo. En estos momentos, por lo tanto, los trabajos de restauración están interrumpidos, quedando aún tres galeras sin tratar. Y, lo que en nuestra opinión es más importante, el proyecto de musealización ha sido abortado; ni siquiera se llegó a completar el inventario riguroso de toda la colección.

Ésa es la razón por la que he decidido publicar estos primeros resultados, a pesar de que el trabajo no haya concluido en su totalidad.

\section{La definición de los criterios y objetivos del método de trabajo}

El Proyecto de Conservación de las Galeras Reales portuguesas definió desde el primer momento un método de trabajo basado en un conjunto de criterios elementales para la conservación contemporánea. De entre ellos, destacamos en primer lugar el respeto hacia el original, pero también la consideración de cuatro principios fundamentales: el de intervención mínima, el de la compatibilidad entre materiales originales y materiales actuales, el principio de reversibi- 

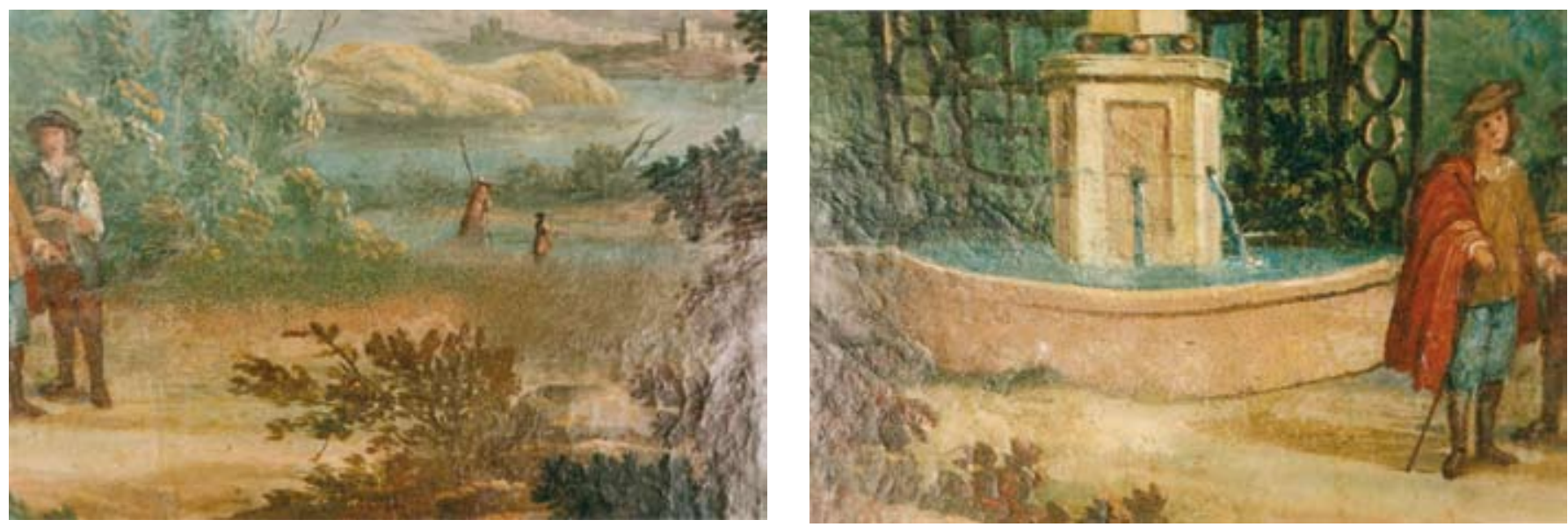

Proceso de integración cromática de la pintura con paisaje bucólico del interior del camarín real. Fotos: Lorena Sancho Querol

lidad y el del reconocimiento de la intervención realizada. Aunque nos pueda parecer irreal, era la primera vez que se planteaban estos principios para esta colección de embarcaciones históricas, que nunca había tenido el privilegio de ser considerada desde la perspectiva del respeto por su dimensión, material e inmaterial.

Los objetivos de nuestro proyecto fueron, por una parte, estudiar la colección desde una perspectiva antropológica, procediendo a la divulgación, en el contexto museológico, del conjunto de realidades pasadas y presentes que ayudan a satisfacer lo que Mario Chagas identifica como deseo de memoria, deseo de patrimonio y deseo de museo $^{6}$, por parte del público, creando, a partir de este patrimonio vivo, una comunicación cultural basada en el respeto a la diversidad histórica y social. Por otra parte, divulgar el proyecto mediante la apertura al público de los trabajos prácticos en curso y el contacto directo con los visitantes, con un conjunto de actividades didácticas que permitiesen explorar y explotar este atractivo campo de actuación.

Con el paso de los años fue posible contar con la colaboración del Departamento de Investigação do Museu de Marinha; los talleres de construcción de miniaturas navales de ese mismo Museo; y la eventual colaboración del Laboratorio de Química de la Facultad de Ciencias y Tecnología de la Universidade Nova de Lisboa. En el proyecto inicial estaba prevista la realización de un protocolo con esta universidad para apoyo a la investigación en el área de la ciencia de los materiales.

\section{LOS RESULTADOS OBTENIDOS}

Teniendo en cuenta que la intervención de restauración realizada en cada una de las dos embarcaciones ha sido excesivamente larga y compleja como para ser transmitida en su integridad, hemos optado por presentar el capítulo más importante desde el punto de vista técnico, de cada una de las dos fases ya acabadas.

De la I Fase presentaremos el proceso de restauración de la pintura al óleo que decora la pared posterior de la segunda sala del interior del camarín real, por tratarse de una composición excepcional que, debido a su desgaste natural y a la importancia de su papel decorativo en un contexto social como el real, sufrió un elevado número de intervenciones que acabarian por transformar su aspecto original.

De la II Fase presentaremos la restauración del elemento de talla dorada más emblemático de la embarcación: la figura de mitología marina que decora la proa de la embarcación.

\section{El proceso de restauración del Bergantín Real}

La restauración del Bergantín Real es uno de esos raros casos que nos ofrece la oportunidad de sumergirnos a fondo en la historia, una de esas excepciones en las que el descubrimiento de los gestos del pasado nos emociona y sorprende a cada paso. En definitiva, un privilegio para la conservación y una gran ocasión para la museología contemporánea.

El carácter experimental del proceso supuso desde el primer momento un bello desafío para nuestro equipo. Si por un lado estaba en juego la conservación de un conjunto extraordinario de bienes museológicos y la formulación de un método adecuado de trabajo, por otro lado lo estaba el establecimiento de un diálogo fluido con la historia, así como la producción de nuevos conocimientos a partir de este estudio.

Para ilustrar este apartado hemos seleccionado algunas imágenes cuya fuerza narrativa permite comprender los diferentes grados de dificultad por un lado y de alegria, por otro, que hemos atravesado.

Hubo incluso quien tuvo dificultad para creer que lo que la restauración había sacado a la luz siempre hubiese estado alli. Esto sucedió tras la fase de limpieza de la pintura que decora la cobertura del camarín real, de manera que parte del personal del Museo llegó a considerarnos poco más que pintoras habilidosas, tras los resultados conseguidos durante la restauración del friso decorativo del exterior de la embarcación. Por último, y muy a nuestro pesar, hubo momentos de decisiones difíciles en las que el pasado volvió a su estado fugitivo. Esto sucedería con el conjunto de talla dorada que decora el exterior del camarin real de la embarcación, 


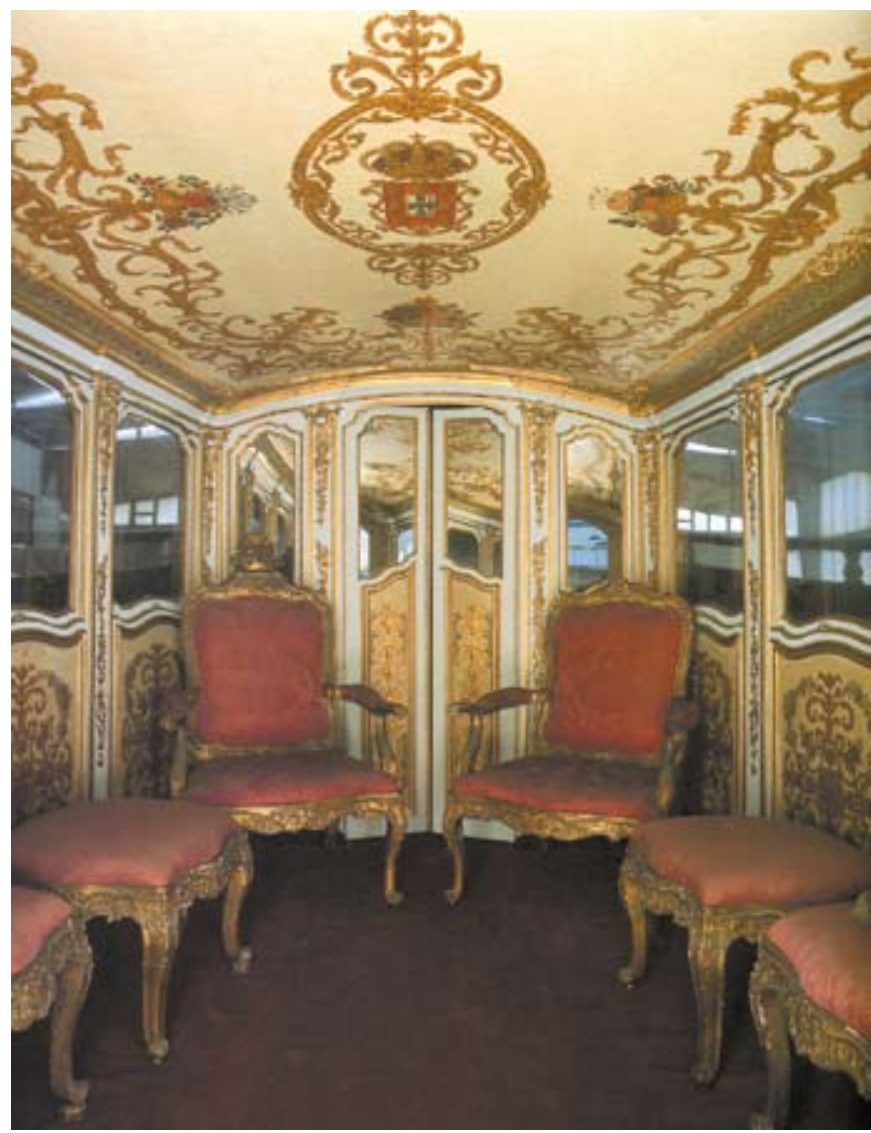

Interior de la sala principal del camarín del Bergantín Real, antes de la intervención. Foto: Lorena Sancho Querol

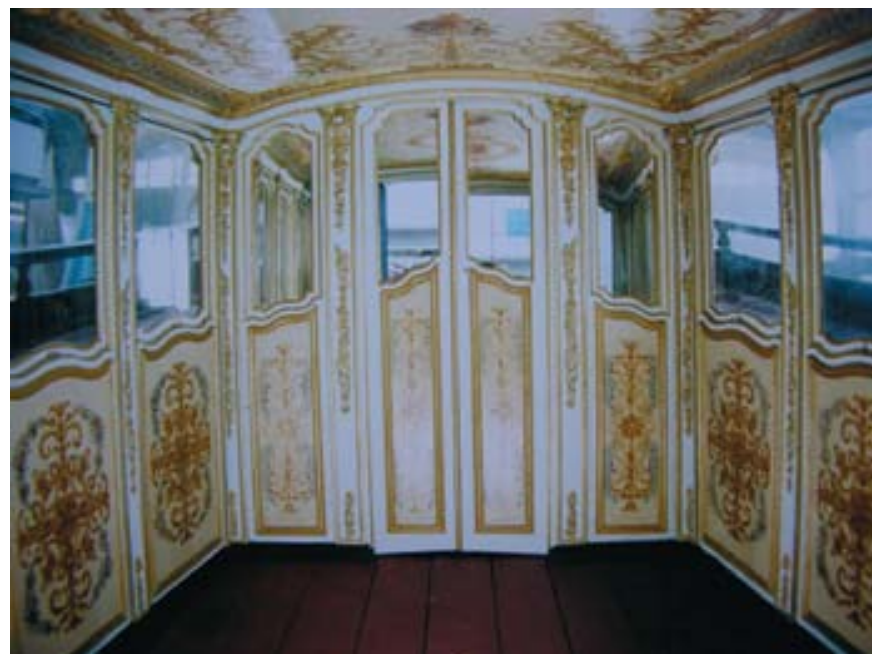

Sala principal del camarín del Bergantín Real, tras la intervención. Foto: Lorena Sancho Querol

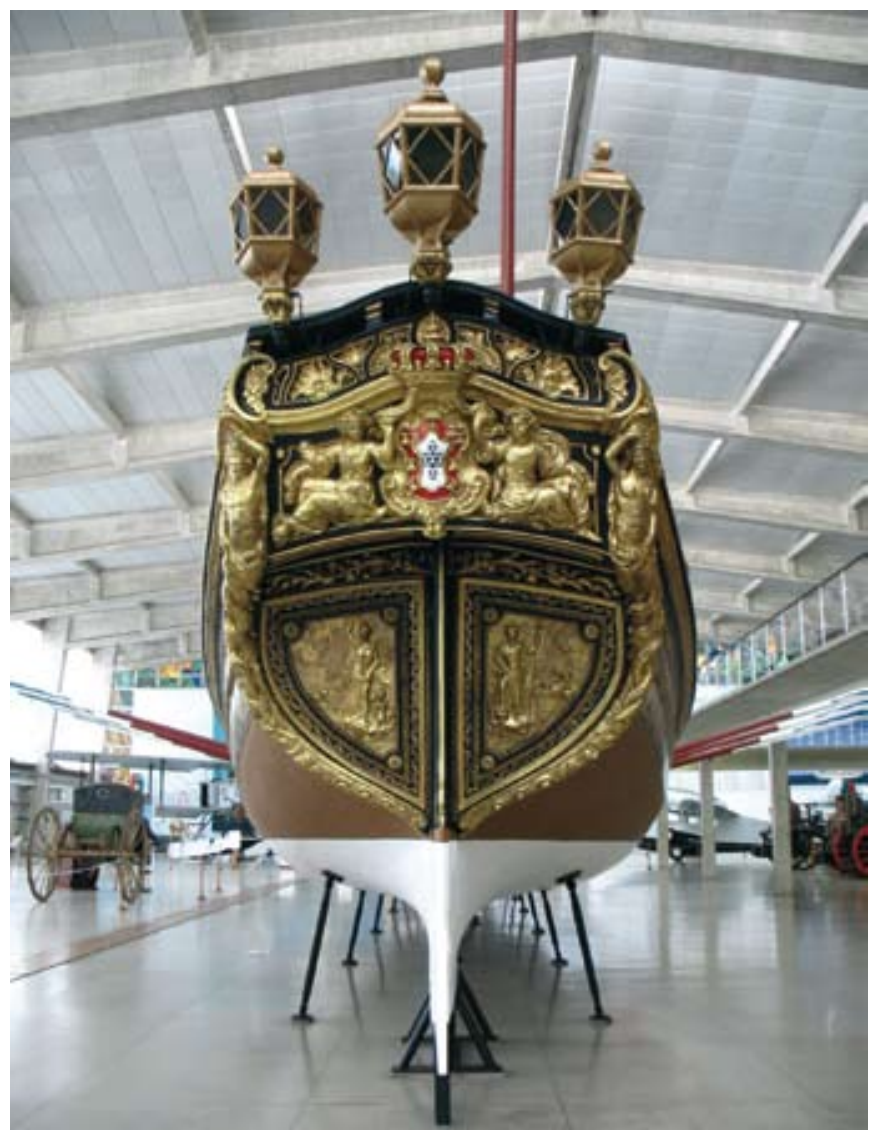

Vista del panel de popa del Bergantín Real después de la restauración. Foto: Lorena Sancho Querol

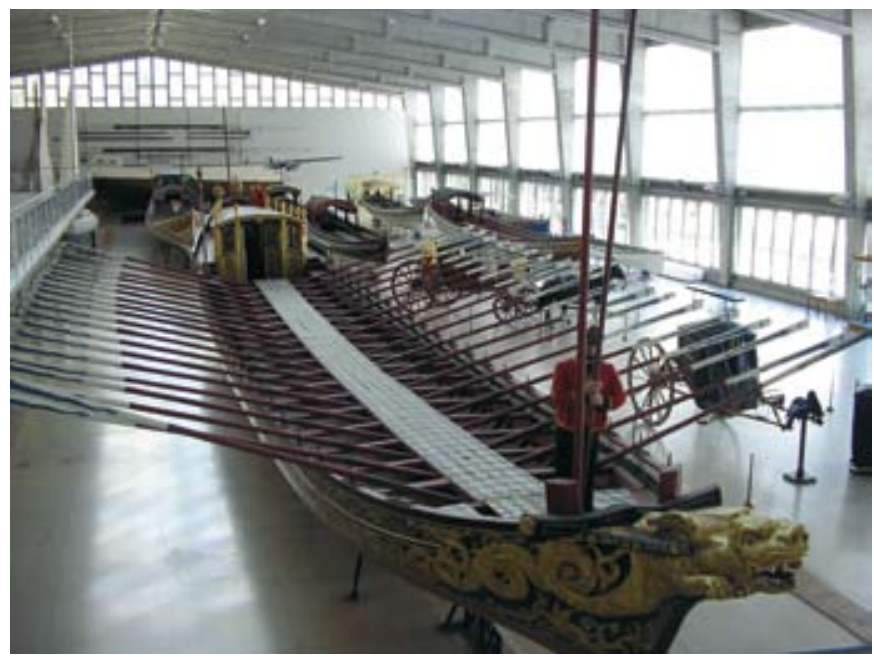

Aspecto general del Bergantín Real finalizada la intervención, en marzo de 2008. Foto: Lorena Sancho Querol

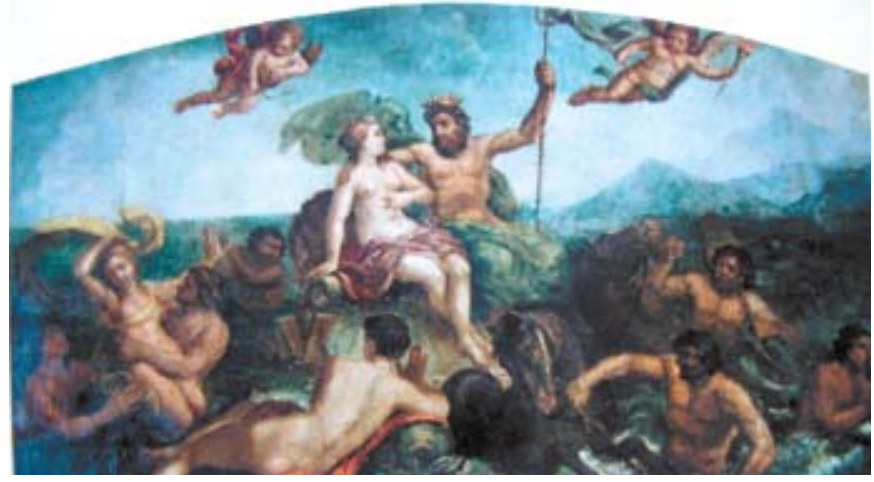

Pintura al óleo sobre tela que decora el panel trasero del camarín del Bergantín Real, antes (izquierda) y después (derecha) de la intervención.

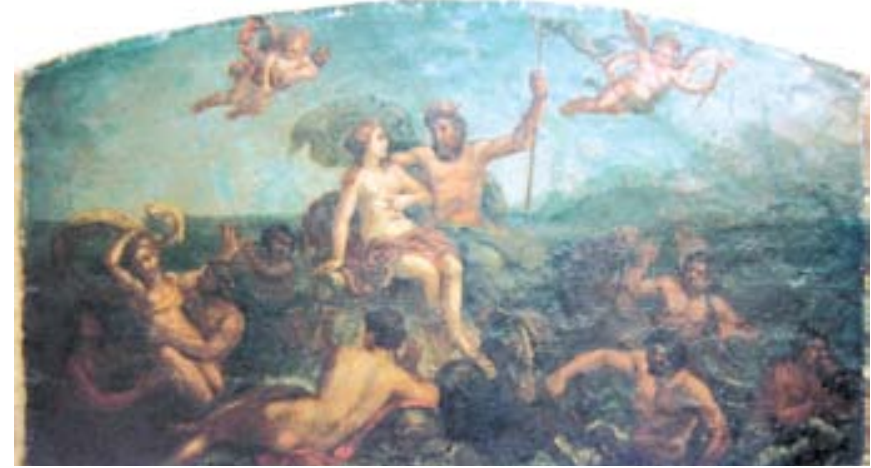


tras verificarse el pequeño porcentaje de oro fino original que sobrevivía en una capa disfrazada por los avatares de la historia.

\section{Restauración del paisaje bucólico del interior del camarín real}

El ejemplo escogido ilustra la intervención realizada en la pintura al óleo que decora la pared del fondo de la segunda sala del camarin real, representando un paisaje bucólico de estilo realista.

Según la investigación realizada, esta salita asumía la función de aseo. Los objetos necesarios para esta función fueron fabricados en plata y llevan el nombre del Bergantín Real grabado en su exterior. Se encuentran actualmente en los fondos del Museo.

Su interior se encuentra integramente decorado por paisajes en los que el agua tiene una presencia fundamental, encontrándose unidos todos ellos como si de un único paisaje se tratase. De entre estos motivos, el que aqui nos ocupa es sin duda el gran protagonista de la composición, además de ser el más visible de todos. Quizás sea esta la razón por la que ha llegado a nuestros dias habiendo sufrido un total de cuatro intervenciones pictóricas, en cada una de las cuales fueron alterados los valores originales de esta obra.

La composición que aqui presentamos constituye la única parte de la decoración de esta sala en la que aparecen representadas, a la altura del segundo plano, dos figuras masculinas. Sobre la identidad de estos personajes, nada hemos conseguido saber hasta hoy.

Sabemos que el autor de este paisaje fue el pintor Pedro Alexandrino de Carvalho y que se realizó sobre tela de lino, sobrepuesta a un total de cuatro travesaños de madera de sucupira (Pterodon emarginatus) que forman la pared posterior del camarín real. Se trata de un paisaje bucólico extremadamente realista para la época. En primer plano se encuentran dos conjuntos arbóreos y, en segundo plano y a la izquierda, una fuente de piedra junto a la cual conversan las dos figuras antes mencionadas. En un tercer plano y a la derecha se observa un bello paisaje montañoso dominado por la presencia de un lago donde otros dos personajes parecen practicar la pesca. Al fondo, entre las montañas, podemos ver un castillo que enriquece la composición; por último, en la zona superior vemos un maravilloso escenario donde las nubes ganan vida a través de un excepcional estudio de luces y sombras que nos recuerda, en cierta manera, los pormenores de la pintura flamenca del siglo XVI, precursora de este género.

\section{El estado de conservación}

La obra presentaba un estado de conservación muy deficiente del que podriamos destacar los daños más evidentes en dos niveles: respecto al soporte, las deformaciones propias de un conjunto de paneles de madera ensamblados y sometidos a contextos de humedad relativa y temperatura muy variables; respecto a los estratos cromáticos, los daños más relevantes eran, por un lado, la presencia de un conjunto de alteraciones pictóricas realizadas sobre la composición original, especialmente evidentes en la zona superior, donde las nubes habian perdido por completo su volumetría original y donde nada quedaba del magnífico estudio de luces y sombras que enriquecia la composición; por otro, la existencia de una red de fisuras de dimensión y profundidad diversa, y la presencia de varios clavos de hierro en avanzado estado de oxidación, repartidos por el conjunto.

A esto debemos añadir el avanzado estado de oxidación de la película protectora y la capa de suciedad que sobre ella se encontraba acumulada.

\section{La intervención realizada}

Como punto de partida y ante la presencia de un número indeterminado de capas pictóricas de calidad y procedencia diversa, fueron realizados dos análisis estratigráficos que permitiesen identificar las superposiciones. A partir de estos datos y de su interpretación, procedimos a la realización de un conjunto de ventanas de limpieza que nos permitiesen confirmar la existencia y el estado actual del motivo original subyacente.

En una fase inicial y previa a los análisis, fueron fijadas todas las zonas de la capa pictórica que se encontraban alteradas. Posteriormente se hicieron los análisis que permitieron identificar un total de cuatro capas de repintes diferentes acompañadas de sus respectivas capas de protección, en la zona superior de la composición. Con estos resultados a la vista fue posible proceder a la limpieza de la capa pictórica y a la consecuente eliminación de los repintes existentes en esta zona. Los repintes situados en el primer plano, en los laterales de la composición, no fueron eliminados por haberse comprobado la inviabilidad de este tipo de intervención, debido fundamentalmente a la ausencia de motivo original subyacente.

El tratamiento estético realizado tuvo como primer objetivo la estabilización de los materiales previos, que serian respetados en nuestra intervención: clavos de hierro, repintes históricos y parches estructurales entre otros. Para terminar $y$, tras el tratamiento volumétrico de los diferentes tipos de lagunas, se realizó una reintegración cromática diferenciada a base de puntillismo en la totalidad de las lagunas existentes.

\section{El proceso de restauración de la Galera de don Juan V}

Del proceso de restauración de la Galera de don Juan V podemos decir que, a pesar de ser la embarcación más antigua de esta colección, la intervención realizada raramente llegó a plantear tantas dificultades como en el caso del Bergantín Real. A pesar de poseer un ciclo vital más corto, el Bergantín Real había sido exageradamente alterado a lo largo de la historia, tanto en forma como en contenido. La Galera de don Juan V, salvo excepciones 


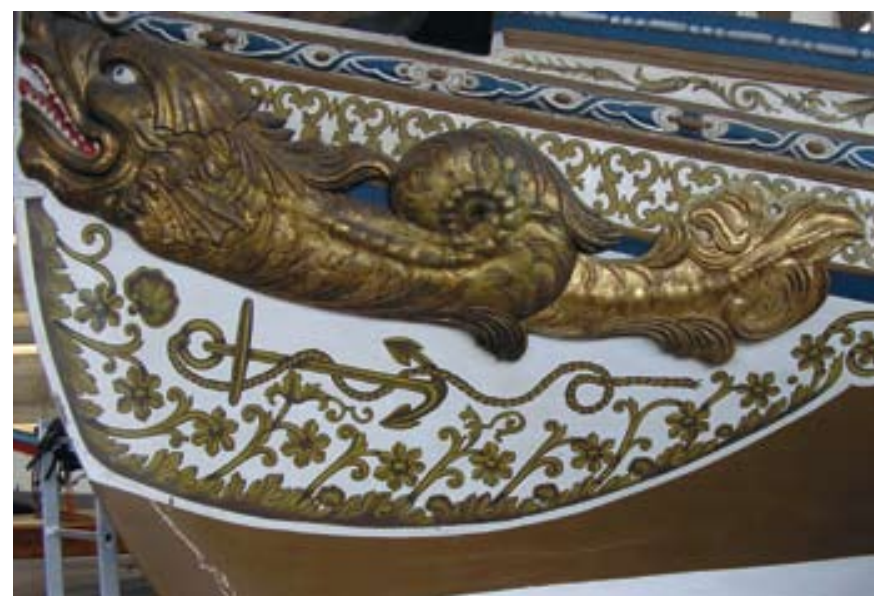

Limpieza de la figura de proa estribor en la Galera de don Juan V. Foto: Lorena Sancho Querol

como la restauración de la pintura que decora el baldaquín de la embarcación, fue de hecho una intervención tranquila. Para la restauración de los diferentes tejidos que decoraban el camarín real de esta embarcación, el equipo técnico contó con la colaboración de uno de los mejores especialistas del país en restauración de tejidos, Luís Filipe Monteiro.

\section{La restauración de la figura de proa}

La figura de proa de esta galera representa una imagen de la mitología marítima que podemos fácilmente identificar como un dragón marino. Se trata de un bajorrelieve realizado en madera de sucupira que, en su origen, y según la información obtenida a través de los exámenes realizados, se encontraba toda ella decorada con oro fino bruñido, según la técnica de dorado barroca.

\section{El estado de conservación}

La obra presentaba un estado de conservación razonable. Por lo que respecta al soporte de madera, no existian factores de riesgo relevantes. En cuanto a los estratos cromáticos, hay que destacar la presencia de un total de tres capas de purpurina dorada y de goma-laca sobre la capa de oro fino original que, al comienzo de la intervención, se encontraban en un estado muy avanzado de oxidación, con señales evidentes de diversas alteraciones físicoquímicas. Conviene destacar igualmente que en el lado de babor existían indicios de aplicación de oro fino procedentes de una de las últimas intervenciones realizadas -probablemente en la época en que todavía se encontraba en uso- y que, tanto a estribor como a babor, no se observaba la presencia de capas protectoras.

Por último, hay que anotar la existencia de una considerable red de fisuras, de diferentes tamaños y profundidades, y la presencia de una gruesa capa de suciedad de diversa naturaleza, solidificada.

\section{La intervención realizada}

En una fase inicial y tras confirmar la naturaleza y caracteristicas de las diferentes capas decorativas, se realizó una limpieza que

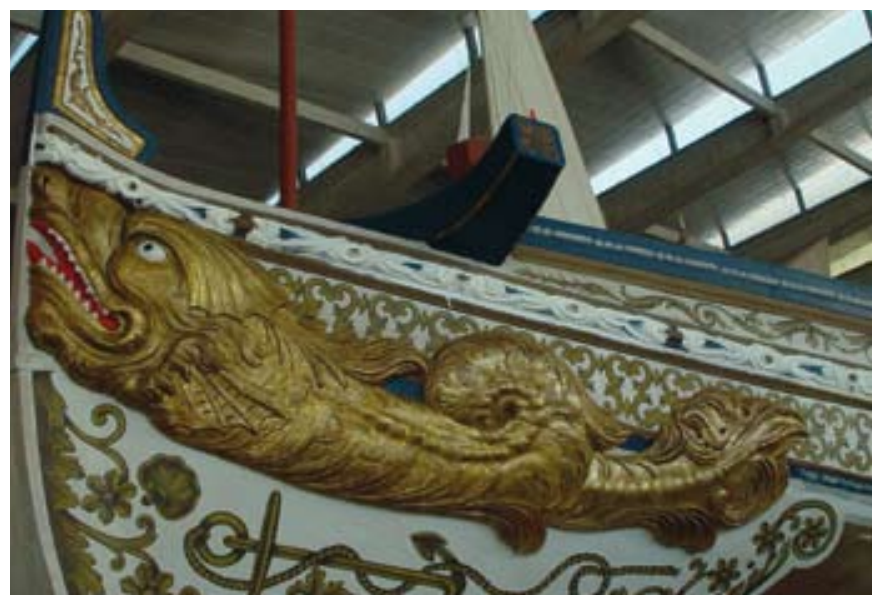

Figura de proa estribor en la Galera de don Juan $\vee$ tras la restauración. Foto: Lorena Sancho Querol

nos permitiera dejar a la vista la última capa de oro fino aplicada sobre esta figura.

Esta opción, si tenemos en cuenta el contexto en el que estaba teniendo lugar la intervención, fue la única viable desde los puntos de vista histórico y estético ya que, de la decoración original, apenas restaban minúsculos porcentajes de oro fino a los cuales era extremamente difícil y arriesgado llegar.

En todas aquellas zonas donde no fue posible dejar a la vista un estrato decorativo con historia propia se llevó a cabo una integración cromática diferenciada a base de puntillismo con oro fino en polvo; para terminar fue aplicada una capa de protección a base de resina sintética de elevada estabilidad físico-química.

\section{CON LA MIRADA EN EL FUTURO}

A lo largo de los casi seis años durante los que he tenido la oportunidad de colaborar con el Museo de la Marina en éste y en otros proyectos, he podido comprender la importancia que este patrimonio tiene para el pueblo portugués y para el público venido de las más diversas partes del mundo en una ciudad tan turística como Lisboa. La historia marítima de los portugueses es sin duda increíble, pero más increible resulta que parte de este Patrimonio haya sobrevivido hasta nuestros dias y que, además, el público vaya a su encuentro.

En este mismo instante, las Galeras Reales, en la serenidad de su pacífica existencia, suscitan asombro e interés a quien a ellas se está aproximando, levantan dudas y crean cuestiones de la más diversa indole a un público ávido de respuestas. Un público que, en su momento, nos abordaba espontáneamente con todo tipo de preguntas, un público a quien el equipo respondía con agrado mostrando las múltiples perspectivas del proceso en curso, que nos hizo sentir orgullo por la resurrección de la que estábamos siendo autoras.

Ahora, con el proyecto parado, además de pensar con preocupación, por supuesto, en el pésimo estado de conservación de las Galeras que quedan por restaurar, pienso a menudo en ese 
público, padres que visitaron siendo niños ese Museo y que una generación después llevaban a sus propios hijos e hijas para que vivieran una experiencia singular, una experiencia donde los protagonistas son el mar, el ingenio, la aventura, el arte, la valentía, la historia por descubrir y el deseo de comunicación con todo ello que el visitante trae guardado en su bolsillo.

Queda mucho por hacer y es sin duda necesario el ejercicio de una dinámica museológica específica para el entendimiento de esta colección y de su contexto histórico, del que todavia tenemos varios enigmas por descifrar. Quizás el estudio de esta y de otras realidades de éste y de otros museos, puedan ayudarnos a entender algunos aspectos maravillosos del devenir de nuestra existencia humana, con olor a mar.

Proyectos como éste no son más que pequeños retos para la restauración y para la conservación del Patrimonio cultural; sin embargo son, por encima de todo, un gran reto para la propia Museología. Espero sinceramente que la presión que ese público fiel pueda ejercer sobre las autoridades de la Marina portuguesa suponga un empujón definitivo para la continuación de este proyecto. Ese público lo merece, pero también lo merecen las propias Galeras y, sobre todo, el Patrimonio marítimo portugués.

\section{Notas}

${ }^{1}$ Lo confirman las fotografías que se encuentran en la exposición de trofeos cinegéticos del Palácio de Vila Viçosa, cerca de Évora.

${ }^{2}$ Información obtenida durante la entrevista realizada el día 22 de mayo de 2007, con el apoyo y la colaboración del director de la Revista da Armada, Contra-Almirante EMO Luis Augusto Roque Martins, al pintor naval Luis Cândido Teixeira, antiguo funcionario del Arsenal do Alfeite y autor de las intervenciones realizadas en 1974 y en 1987.

${ }^{3}$ Ibídem.

${ }^{4}$ El World Ship Trust es una organización internacional cuyo objetivo es motivar al público a apreciar su herencia maritima, a través de la recuperación y de la preservación de embarcaciones históricas. Bergantim Real distinguido com Prémio Internacional, Revista da Armada, enero 1998, № 305, p. 27.

${ }^{5}$ Ver conclusiones del Estudio de Públicos realizado en la tesis de maestrado titulada La función social del Patrimonio Marítimo Portugués, Lorena Sancho Querol, Universidade Lusófona de Humanidades e Tecnologias, Lisboa, 2005.

${ }^{6}$ Comunicación personal sobre Diversidade museal e movimentos sociais, Doctorado en Museologia, Universidade Lusófona de Humanidades e Tecnologias, 11/04/08.

\section{Bibliografía}

AA.W. (2001) A Marinha na Investigação do Mar 1800-1999. Lisboa : Instituto Hidrográfico, 2001

BARBOSA, J. DE V. (1875). Estudos históricos e arqueológicos. Tomo II. Porto : Tipografia de José da Silva Teixeira, 1875

BERGANTIM Real distinguido com Prémio Internacional. Revista da Armada, ${ }^{\circ}$ 305, 1998, Janeiro, p. 27

BOUZA, F. (2005). Reis de Portugal. 3a Dinastia. D. Filipe I. Rio de Mouro : Circulo de Leitores e Centro de Estudos dos Povos e Culturas de Expressão Portuguesa, 2005

CHAGAS, M. S. (2007) Museus, memórias e movimentos sociais; Os museus e a radiosa aventura. Textos inéditos facilitados por el autor en el contexto de Doctorado en Museologia, ULHT

CLIFFORD, J. (1997) Routes: Travel and Translation in the late Twentieth Century. Cambridge and London : Harvard University Press, 1997
COUTINHO, G. (1942) Gago Coutinho reclama uma instalação condigna para as maravilhosas galeotas reais. Revista de Marinha, no 149, 31 de Março, p.1

CRUZ, M. A. L. (2006) Reis de Portugal. 2a Dinastia. D. Sebastião. Rio de Mouro : Circulo de Leitores e Centro de Estudos dos Povos e Culturas de Expressão Portuguesa, 2006

CUTILEIRO, A. (1973) A vida faustosa das Galeotas Reais. Subsidios para a história das antigas embarcações da Casa Real Portuguesa que se guardam no Museu de Marinha. Comunicação apresentada ao Centro de Estudos de Marinha no dia 21 de Abril de 1971. Lisboa : Instituto Hidrográfico, 1973

CUTILEIRO, A. (1998) As Galeotas Reais. Lisboa : Edições Inapa, 1998

ESPARTEIRO, A.M. (1965) Plaquete histórica das Galeotas e Bergantins Reais. Lisboa : Ministério do Ultramar, Direcção-geral de Obras Públicas e Comunicações, 1965

FERREIRA RAMOS, P. (1992) As principais datas da história de Portugal. Mem Martins : Francisco Lyon de Castro, 1992

FREIRE, P. (2000) Pedagogia da Indignação: cartas pedagógicas e outros ensaios. Brasil : UNESP, 2000

GALÉS e Bergantins de Gala dos Reis de Portugal. Revista de Marinha, , 1970, nº 565, pp. 13-16

GOMES, C. E. (1994) Instalações Navais da Azinheira. Revista da Armada, n² 265, 1994, Maio, pp.17-20

HOMS, Ma I. P. (2004) Pedagogia museística, Nuevas perspectivas y tendencias actuales. Barcelona : Ariel, 2004 (Patrimonio)

INAUGURAÇÃo do heliporto nas instalações da Azinheira. Revista da Armada, № 281, 1995, noviembre, pp. 14-15

INSTITUTO Hidrográfico. Azinheira. Espaço e Tempo. Lisboa : Instituto Hidrográfico, 2007

LAVANHA, J. B. (1622) Viagem da Cathólica Real Magestade del rey D. Felipe II N.S. ao reyno de Portugal, Madrid

LEITÃO, U.; LOPOES, J. V. (1990) Dicionário da Linguagem de Marinha Antiga e Actual. Lisboa : Centro de Estudos Históricos e Cartografia Antiga, Edições Culturais da Marinha, 1990

LOPÉZ SALAS, F. (1980) El Museo, cultura para todos. Cultura y Comunicación, $n^{\circ} 13$, p. 36

MUSÉE DU QUEBEC / MUSEÉ DE LA MARINE (2001). Les Génies de la Mer. Canadá : Museé du Quebec

OLIVAL, F. (2005) Reis de Portugal. $3^{a}$ Dinastia. D. Filipe II. Rio de Mouro : Circulo de Leitores e Centro de Estudos dos Povos e Culturas de Expressão Portuguesa, 2005

OLIVEIRA, A. (2005) Reis de Portugal. 3a Dinastia. D. Filipe III. Rio de Mouro : Circulo de Leitores e Centro de Estudos dos Povos e Culturas de Expressão Portuguesa, 2005

RAPOSO, L. (2007) Acerca da problemática subjacente à definição de tesouros nacionais. Museologia .pt, no 1, Maio 2007, pp.13-23.

SANCHO QUEROL, L. (2007) Conservação e Museologia de mãos dadas no Museu de Marinha. O Projecto de Conservação das Galeotas Reais. Revista da Armada No 409, 2007, Junho, pp. 24-26

SANCHO QUEROL, L. (2007) Conservação e Museologia de mãos dadas no Museu de Marinha. 0 Projecto de Conservação das Galeotas Reais. 0 restauro do Bergantim Real - 1a parte. Revista da Armada, n 410, 2007, Julho, pp. 25-28

SANCHO QUEROL, L. (2007) Conservação e Museologia de mãos dadas no Museu de Marinha. 0 Projecto de Conservação das Galeotas Reais. 0 restauro do Bergantim Real - 2a parte. Revista da Armada no 411, 2007, Agosto, pp. 25-27

SANCHO, J. L.; VALVERDE J. L.; DE URRÍES, J. J. (2006) Guía del Real Sitio de Aranjuez. Reales Sitios de España. Madrid : Patrimonio Nacional, 2006

SANTOS, Ma C. M. (1999) Estratégias Museais e Patrimoniais contribuindo para a qualidade de vida dos cidadãos: diversas formas de musealização. Salvador da Bahia : Comunicação apresentada no VIII Atelier do MINOM, 1999

SILVA, G. C. (2007) A última missão do Bergantim Real. 1. Entradas Régias. Revista da Armada, nº 405, 2007, Fevereiro, pp. 18-20

SILVA, G.C. (2007) A última missão do Bergantim Real. 2. 0 desembarque da Rainha de Inglaterra. Revista da Armada, no 406, 2007, Março, pp. 16-18

SILVEIRA, L. N. E.; FERNANDES, P. J. (2006) Reis de Portugal. $4^{a}$ Dinastia. D. Luís. Rio de Mouro: Circulo de Leitores e Centro de Estudos dos Povos e Culturas de Expressão Portuguesa, 2006

SOUSA, M. (2000) Reis e Rainhas de Portugal. Lisboa : Sportpress, 2000

VIAJE de SS. MM. y AA. a Portugal en diciembre de 1866. [S.I.] bs.n.]: 1867(Madrid):Rivadeneyra, 1867, pp. 186-201

ZUBIAUR, F. J. C. (2004) Curso de Museología. Gijón: Trea, 2004 